\title{
DiscoverArchive
}

Retrieved from DiscoverArchive,

Vanderbilt University's Institutional Repository

This work was originally published as W. Kip Viscusi, Policy Challenges of the Heterogeneity of the Value of Statistical Life in 6(2) Foundations and Trends in Microeconomics 992010. 
Foundations and Trends ${ }^{\circledR}$ in

Microeconomics

Vol. 6, No. 2 (2010) 99-172

(C) 2011 W. K. Viscusi

DOI: $10.1561 / 0700000011$

\section{Policy Challenges of the Heterogeneity of the Value of Statistical Life}

By W. Kip Viscusi

\section{Contents}

1 Introduction

101

2 Calculating the Value of Statistical Life (VSL)

104

3 Heterogeneity of VSL Based on the Risk Level

108

4 Segmented Labor Markets

5 Heterogeneity Based on Age

6 Value of a Statistical Life Year (VSLY)

6.1 The VSLY Approach

6.2 An Application of VSL and VSLY to the Private Cost of Cigarettes

7 Income Effects 
9 The "Senior Discount" Controversy

10 Should Income Levels Matter?

133

11 The Devaluation of Life Controversy

136

12 Adjustments for the Size of Risk

139

12.1 Risk Levels in Hedonic Wage Studies

12.2 A Calibration Example for Non-Incremental Risk Changes

143

13 Latency and Cancer Benefit Issues

14 Dread and Contextual Sources of Variation in Valuing Life: Deaths from Attacks by Terrorists

152

15 Should the VSL Be Added to the Present Value of Economic Damages?

160

16 Conclusion

164

References

166 
Foundations and Trends ${ }^{\circledR}$ in

Microeconomics

Vol. 6, No. 2 (2010) 99-172

(C) 2011 W. K. Viscusi

DOI: $10.1561 / 0700000011$

\title{
Policy Challenges of the Heterogeneity of the Value of Statistical Life*
}

\author{
W. Kip Viscusi \\ University Distinguished Professor of Law, Economics, and Management, \\ Vanderbilt University Law School, 131 21st Avenue South, Nashville, TN \\ 37203,USAkip.viscusi@vanderbilt.edu.
}

\begin{abstract}
Economic research has developed estimates of the heterogeneity of the value of statistical life (VSL) on dimensions such as individual age, income, immigrant status, and the nature of the risk exposure. This paper examines the empirical evidence on the heterogeneity of VSL and explores the potential implications for the valuation of regulatory policies. Previously, the U.S. Environmental Protection Agency (EPA) unsuccessfully sought to adopt a simple age discount percentage for VSL based on survey evidence. However, labor market estimates of VSL indicate a pattern that tracks lifetime consumption trajectories, as the VSL rises with age and eventually tapers off but does not plummet with age. The VSL has an income elasticity of at least 0.5. The analysis of age variations in VSL is accompanied by a review of the value of statistical life year (VSLY) approach. The U.S. Department

* Preliminary versions of the paper were presented at the CREATE - DHS Conference, Washington, D.C., September 23-24, 2010, and at the ALEA Conference in New York City, May 20, 2011.
\end{abstract}


of Transportation recognizes the influence of a positive income elasticity of VSL, and EPA has proposed adopting a 50\% cancer premium. Recent studies suggest that the risk of death from terrorist attacks are of particular concern and may merit a substantial premium in benefit assessments. Whether and how such heterogeneity in VSL should be incorporated in regulatory policy evaluations depends in part on the source of the heterogeneity. Some prominent sources of heterogeneity arise from segmented labor markets in which disadvantaged groups face different labor market opportunities. Blacks and Mexican immigrants face quite different labor market offer curves. As a result, influences that are problematic from the standpoint of setting different benefit levels for policy purposes are differences in VSL by race and immigrant status. The paper also examines the EPA's recent devaluation of life and the Posner-Sunstein proposal to use VSL estimates to set hedonic damages in tort liability cases. As with hedonic damages generally, adoption of their proposal would lead to excessive levels of compensatory damages and would greatly increase damage amounts.

Keywords: Value of statistical life, risk, regulation, hedonic damages.

JEL Codes: J17, I18, H40, K32 


\section{Introduction}

The value of a statistical life (VSL) is the individual's money-risk tradeoff for small risks of death. This measure is the most prevalent benefit assessment approach used by government agencies when valuing changes in risk. The academic literature includes dozens of labor market studies of VSL. ${ }^{1}$ There also have been studies of VSL based on price-risk tradeoffs for the product market as well as VSL amounts implied by risk-taking decisions ranging from the choice of highway speed to the use of seat belts.

This paper focuses on the variation in VSL both across different studies in the academic literature as well as in different policy contexts. These differences often reflect quite legitimate heterogeneity in the valuation of risk. There are important differences in the VSL with respect to individual risk-taking behaviors as well as personal characteristics, including age, income, race, gender, and immigrant status. What are these differences and what are the policy implications for benefit

\footnotetext{
${ }^{1}$ For reviews, see Viscusi (1993), Viscusi and Aldy (2003), and Viscusi (2010), among others. Robinson (2007), Graham (2008), and Viscusi (2009a) review related government agency practices. Kniesner and Leeth (2009) review the underlying theory and econometric foundations of this area of research.
} 
assessment? To assess such issues, I explore both the VSL estimates themselves and their implications for the structure of labor markets. The ramifications for labor market structure are not innocuous. To the extent that there are segmented labor markets in which people face different labor market opportunities, there will be differences across the population in their estimated VSL. How and whether information regarding the heterogeneity of VSL should be used depends on how the differences arise.

My review of the academic literature is coupled with an examination of the policy arena's use of the VSL methodology. Government agencies adopted the VSL approach to valuing risk regulations almost three decades ago. The use of VSL estimates to value mortality risks has continued through the recent controversies involving variations in VSL levels with age and income. Other aspects of risk heterogeneity that also are potentially prominent policy concerns and could affect the application of VSL estimates include the size of the risk being reduced and the context in which the risk arises. For example, is the risk a voluntary risk, and is it being incurred in a market context in which those exposed to the risk have endangered their lives by engaging in reckless behavior?

As government agencies continue to refine their benefit assessment procedure, the potential role of heterogeneity of VSL has moved to the forefront of these debates. The U.S. Department of Transportation (U.S. DOT, 2008) has adopted a positive income elasticity of VSL. The income elasticity of VSL has also arisen as a component in proposed congressional legislation that sought to incorporate a proportional income elasticity of VSL that will apply only to increases in income. $^{2}$ Age variations in the VSL amount used in regulatory impact analyses have been attempted and since abandoned in the United States, ${ }^{3}$ but outside the United States the practice of varying VSL by age has generated less of a controversy. ${ }^{4}$ More recently, the U.S.

\footnotetext{
${ }^{2}$ The 2008 proposed legislation was the "Restoring the Value of Every American in Environmental Decisions Act" (proposed in the 110th Congress, 2nd Session).

${ }^{3}$ See Viscusi (2009a) for a review of the history of this episode.

${ }^{4}$ The European Commission's (2001) member countries use a VSL that declines with age, and Canada has used a VSL involving a $25 \%$ discount for those over age 65 . See Hara Associates (2000).
} 
Environmental Protection Agency (U.S. EPA, 2010) proposed a cancer premium for VSL following a similar approach in the United Kingdom. Other types of differentiation by type of risk exposure, such as terrorism attacks, are also likely to gain policy prominence based on the findings in the economics literature.

The VSL approach continues to remain controversial among noneconomists on normative grounds, as exemplified in the critique by Ackerman and Heinzerling (2004). However, the policy alternative to using VSL estimates has not been to use an infinite value of life but to undervalue lives. In particular, early policy assessments used the economic loss measures in tort damages contexts consisting of the present value of lost earnings and medical expenses. Tort damages alone will undervalue life compared to VSL estimates. There have also been recent suggestions that court awarded compensation for wrongful death should include both the VSL as well as the value of economic loss. One might think that such a measure, if appropriate for compensatory damage purposes, surely would be appropriate for regulatory analyses as well. Whether this expansion of the use of the VSL concept in combination with economic loss amounts is appropriate is explored later in this paper.

Assessments of VSL and heterogeneity in VSL levels are likely to be increasingly important for policy decisions. For three decades agencies have been required to show that all major new regulations pass a benefit-cost test. In 2011, President Obama's Executive Order 13563, Improving Regulation and Regulatory Review, reaffirmed the objectives of the previous Executive Order 12866 and broadened the regulatory review focus and the tests of economic merit to include existing regulations. As a consequence, the range of policies for which benefit-cost tests will be undertaken will continue to increase. That development will bolster the policy role of VSL, which is the standard governmental approach to monetizing mortality risks. 


\section{Calculating the Value of Statistical Life (VSL)}

Because the VSL concept is so widely misunderstood, particularly by critics of the approach, it is worthwhile to begin with the definition of the concept. ${ }^{1}$ The VSL pertains to the tradeoff between money and very small risks of death. In workplace contexts, it is the measure of the average total compensation paid per expected fatality. Suppose that there is a risk of one chance in 10,000 to 10,000 people so that this group will experience one expected death. If each person would be willing to pay $\$ 800$ to eliminate the risk, the VSL in this instance would be $\$ 8$ million, or 10,000 people $\times \$ 800$ per person. This is the amount that could be raised to prevent one expected death. The VSL figure is not an accounting measure of the present value of one's lost earnings. It does not reflect the amount the person would be willing to pay to avoid certain death or the amount that the person would need to be compensated to accept certain death.

Although the VSL terminology is standard in the literature, the U.S. EPA (2010, p. 60) has proposed using the terminology "value of mortality risk (VMR), scaled to micro-risk reductions." The economic

\footnotetext{
${ }^{1}$ See Ackerman and Heinzerling (2004) for a recent example of such a critique.
} 
concept is unchanged, but their objective in adopting this more unwieldy terminology is to decrease the political sensitivity of the approach.

Although many studies have used survey methods to try to elicit people's risk-money tradeoff, the dominant approach in the economic literature has been to analyze wage-risk tradeoffs. Examining how workers in the labor market value risks offers the advantage of imputing values from actual risk-taking decisions using large samples with detailed data. Properly designed stated preference studies are a useful supplementary technique for valuing many health risks, such as those for which there is no market evidence, including various types of cancer.

The basic idea underlying the theory of compensating wage differentials can be traced back to Adam Smith's theory of labor supply. He theorized that workers would need to be paid more for jobs that are risky or otherwise unpleasant. Two centuries later economists began analyzing these premiums for risk and using these estimates to infer a VSL. The empirical task is to control for the various characteristics of the worker and the job and to isolate how much pay workers receive for extra risk. This approach, which is known as a hedonic wage model, utilizes a conceptual framework in which workers pick an optimal riskwage combination from the available set of opportunities in the labor market. Based on these choices, it is possible to estimate the average wage-risk tradeoff rate across the sample.

Figure 2.1 sketches the identical set of labor market opportunities facing two different workers. The curve $w(p)$ is the market opportunities locus for fatality risk $p$. It is the outer envelope of all the individual firms' offer curves, which indicate the highest wage the firm will offer for any given risk. The envelope of such offer curves consequently represents the highest wage that is offered in the market for any given fatality risk. Workers can choose any wage-risk combination that they would like from this offer curve based on their own preferences.

Let $u(w(p))$ be the utility of income when healthy and $v(w(p))$ be the utility of income if killed or injured on the job, where $u^{\prime}, v^{\prime}>0$ for any given $w(p)$, and $u^{\prime \prime}, v^{\prime \prime} \leq 0$. Then, as shown in Viscusi (1978b, 1979) the observed wage-risk tradeoff based on the worker's optimal 


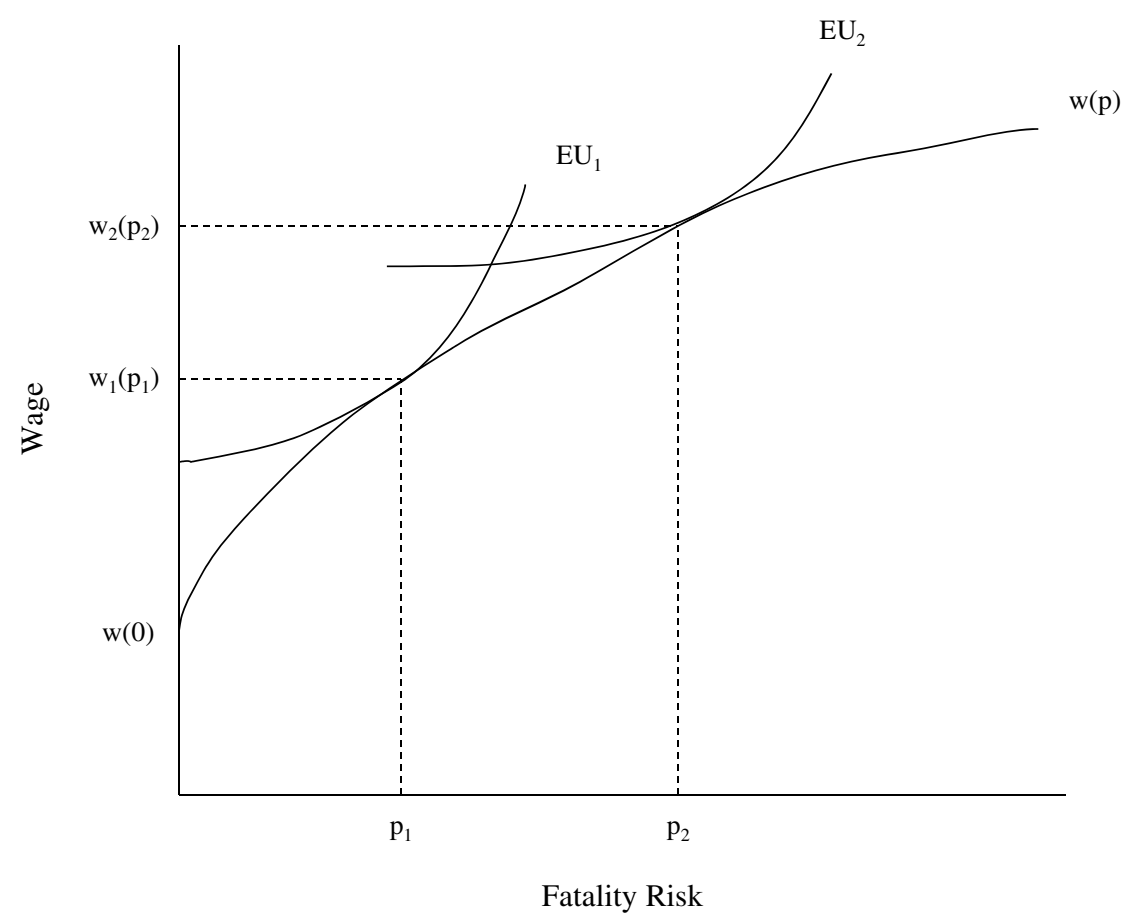

Fig. 2.1 The standard hedonic labor market model.

job choice from the set of available options is given by

$$
w_{p}=\frac{u-v}{(1-p) u_{w}+p v_{w}} .
$$

This equation plays such a fundamental role that it has been "re-discovered" in dozens of subsequent articles. The left side of Equation (2.1) is the VSL for models in which $p$ pertains to the probability of death. The VSL equals the difference in utility levels between the healthy and the ill health or dead state. These utility values are normalized in Equation (2.1) by dividing by the expected marginal utility of income. Empirical estimates usually trace out the average value of $w_{p}$ across the working population using either the log hourly wage or the wage rate as the dependent variable.

There are two workers shown in Figure 2.1. Each worker will choose the wage-risk combination that offers the highest expected utility level given his or her preferences. Worker 1 chooses fatality risk $p_{1}$ that offers 
a wage rate of $w_{1}\left(p_{1}\right)$. Worker 2 is willing to face a higher risk of $p_{2}$ for a wage $w_{2}\left(p_{2}\right)$. The compensating differential that each worker receives for risk is the difference between the wage the worker receives and the value for a risk-free job given by $w(0)$.

Conventional hedonic wage models fit a curve that passes through these various points of tangency, thus simultaneously reflecting the wage-risk tradeoff for both workers and firms. The median estimate of studies using U.S. data is a VSL of $\$ 7$ million ( $\$ 2000$ ) or $\$ 8.7$ million (\$2009) based on the meta analysis in Viscusi and Aldy (2003). Thus, the average worker receives an additional $\$ 870$ to face an annual job fatality risk of $1 / 10,000$. International studies likewise have indicated the presence of compensating differentials in other markets as well. Estimates from labor markets in foreign countries have produced VSL levels in the expected range given that good health is a normal good so that people are less willing to incur health risks as their income level rises. For example, as one would expect, the labor market studies in countries such as India have found a lower VSL than in the United States where income levels are much higher. A review of the international evidence is provided in Viscusi and Aldy (2003). 


\section{Heterogeneity of VSL Based on the Risk Level}

As indicated by Figure 2.1, the wage-risk tradeoff for different workers depends on where they settle along the market offer curve. Worker 1 is on a steeper part of the curve than is Worker 2 and consequently has revealed a higher VSL based on the local wage-risk tradeoff. Workers who gravitate toward higher risk jobs such as those with the fatality risk $p_{2}$ have a lower VSL reflected in their choices.

This heterogeneity in the level of VSL based on the risk level makes it possible to reconcile some of the early differences found in estimates in the literature. For the estimates of the VSL by Thaler and Rosen (1975), the average worker in the sample faced an annual job-related fatality risk of $1 / 1,000$, which is an extraordinarily large fatality risk. ${ }^{1}$ In contrast, the study by Viscusi (1978a,b, 1979) analyzed a more representative group of workers who had fatality risks more in line with the national average at that time, which was $1 / 10,000$. Thus, the ThalerRosen study focused on workers whose risk levels were about an order

\footnotetext{
${ }^{1}$ Because their risk measure was based on life insurance data, it captured all mortalityrelated differences by occupation rather than risks of the occupation per se. The subsequent literature almost invariably has attempted to avoid confounding job risks with personal risks.
} 
of magnitude greater than the U.S. average. The Thaler and Rosen sample of workers had self-selected into very high-risk jobs and are concentrated on the right side of Figure 2.1. Not surprisingly, this focus on workers in very high-risk jobs led to a comparatively low value for VSL. The estimates in Viscusi (1978a, 1979) were five times greater than those in the Thaler-Rosen analysis. ${ }^{2}$

What is interesting about these differences is that the disparate VSL estimates do not arise because of a failure by economists to find "the value of life number." Rather, there is substantial heterogeneity in VSL tradeoffs throughout the labor market, and this heterogeneity is reflected in the different studies. Which particular VSL number emerges from the analysis depends in large part on the composition of the sample and their concentration along the $w(p)$ curve in Figure 2.1.

A major source of heterogeneity of risk preferences can be traced to the risk levels people take as well as individual income levels. Thus, people who gravitate to high-risk jobs are at the lower end of the income distribution and have lower overall wage levels even including the influence of compensating differentials for risk. Using quantile regression analyses and panel data, Kniesner et al. (2010) analyze how the VSL varies across the wage distribution. ${ }^{3}$ People with higher overall levels of wages and income sort themselves into the low-risk jobs and have much higher levels of VSL. As shown by the first column of statistics in Table 3.1, low-wage workers face more than double the fatality risk of high-wage workers.

Whereas the VSL for low-wage workers is only $\$ 3.5$ million, the VSL at the 90th percentile of the wage distribution is $\$ 22.0$ million (\$2001). ${ }^{4}$ These results bolster the implications of the earlier comparison of studies focusing on workers at quite different risk levels. The VSL level differs markedly based on the risk level. Moreover, consideration of the heterogeneity of VSL is not a minor footnote to the VSL

\footnotetext{
${ }^{2}$ See Viscusi and Aldy (2003) for a tabulation of the different estimates. To this day, the Thaler-Rosen estimates remain at the very low end of estimated values from the labor market.

${ }^{3}$ Quantile estimates of the wage-risk relation also appear in Evans and Schaur (2009).

${ }^{4}$ These estimates using the Panel Study of Income Dynamics (PSID) lead to higher levels of VSL than after accounting for person-specific effects and other factors addressed using the panel aspect of the data. See Kniesner et al. (2011).
} 
Table 3.1. Panel quantile estimates of the income elasticity of VSL.

\begin{tabular}{lccccc}
\hline Quantile & $\begin{array}{c}\text { Fatality risk } \\
(\text { per 100,000) }\end{array}$ & $\begin{array}{c}\text { Hourly wage } \\
\text { rate }(\$ 2001)\end{array}$ & $\begin{array}{c}\text { Average family } \\
\text { income }(\$ 2001)\end{array}$ & $\begin{array}{c}\text { VSL }(\$ 2001, \\
\text { millions })\end{array}$ & $\begin{array}{c}\text { Income } \\
\text { elasticity }\end{array}$ \\
\hline 0.10 & 7.83 & 8.66 & 33,583 & 3.46 & 2.24 \\
0.25 & 8.20 & 11.71 & 43,478 & 4.92 & 2.04 \\
0.50 & 7.68 & 17.16 & 57,768 & 7.55 & 1.76 \\
0.75 & 6.07 & 25.09 & 75,762 & 14.55 & 1.20 \\
0.90 & 3.69 & 36.74 & 117,792 & 22.04 & 1.23 \\
\hline
\end{tabular}

Source: Figures in this table are based on data in Kniesner et al. (2010).

literature but is a pivotal concern in determining which VSL is pertinent in any given context. This sorting based on the risk level is also borne out in other risk-taking decisions. By matching individuals' VSL estimates to their decision to use automobile seatbelts, Hakes and Viscusi (2007) found the expected relationship whereby those with a low VSL were less likely to buckle up.

These results have more general implications for what one would expect in terms of differences across the population. People who choose very high-risk jobs, very risky products, or to live in very dangerous neighborhoods have revealed themselves to have lower VSL levels than the average person in society. They have money-risk tradeoff rates such as those for workers located along the right side of the opportunities locus in Figure 2.1. Thus, there is an important influence of selection on job matches. Based on this selection, one can often infer that there are fundamental differences in the risk-money tradeoffs that people are willing to make. Similarly, people whose lives consistently reflect a strong preference for safety are concentrated on the left side of Figure 2.1 and have very steep wage-risk tradeoffs and a high VSL.

A key assumption in this analysis is that people select their job risk based on the available market opportunities independent of the choices of others. One might hypothesize, as some economists have done, that people choose jobs to advance their relative economic position compared to their peers by earning additional income through hazard pay. Kniesner and Viscusi (2005) test this hypothesis and find no empirical support for it. Moreover, while higher income may boost one's status, work on a dangerous and otherwise unpleasant job is likely to have the opposite effect. 
The canonical hedonic labor market model assumes that workers face identical labor market offer curves such as $w(p)$ shown in Figure 2.1. However, Viscusi and Hersch (2001) hypothesize that workers may in fact face different labor market offer curves and as a result settle into separate labor market equilibria. Differences in offer curves with respect to the vertical axis intercept for $w(p)$ will not alter the structure of wage-risk tradeoffs. Such differences are expected since, for example, differences in education levels will lead to different labor market opportunities. What is of greater interest is whether the market offer curves such as that in Figure 2.1 differ in their slopes. A definitive test that Viscusi and Hersch (2001) propose for showing that labor market offer curves differ in their wage-risk tradeoff opportunities is that if workers who face greater risk levels receive less total wage compensation for risk than do workers who face a smaller risk level, then they cannot be on the same market offer curve.

Figure 4.1 provides an illustration of the Viscusi-Hersch labor market model. The workers are in two groups, one of which faces the offer curve $w(p)$, and the other group faces the labor market offer curve indicated in the figure by $v(p)$. As in Figure 2.1, Workers 1 and 2 settle 


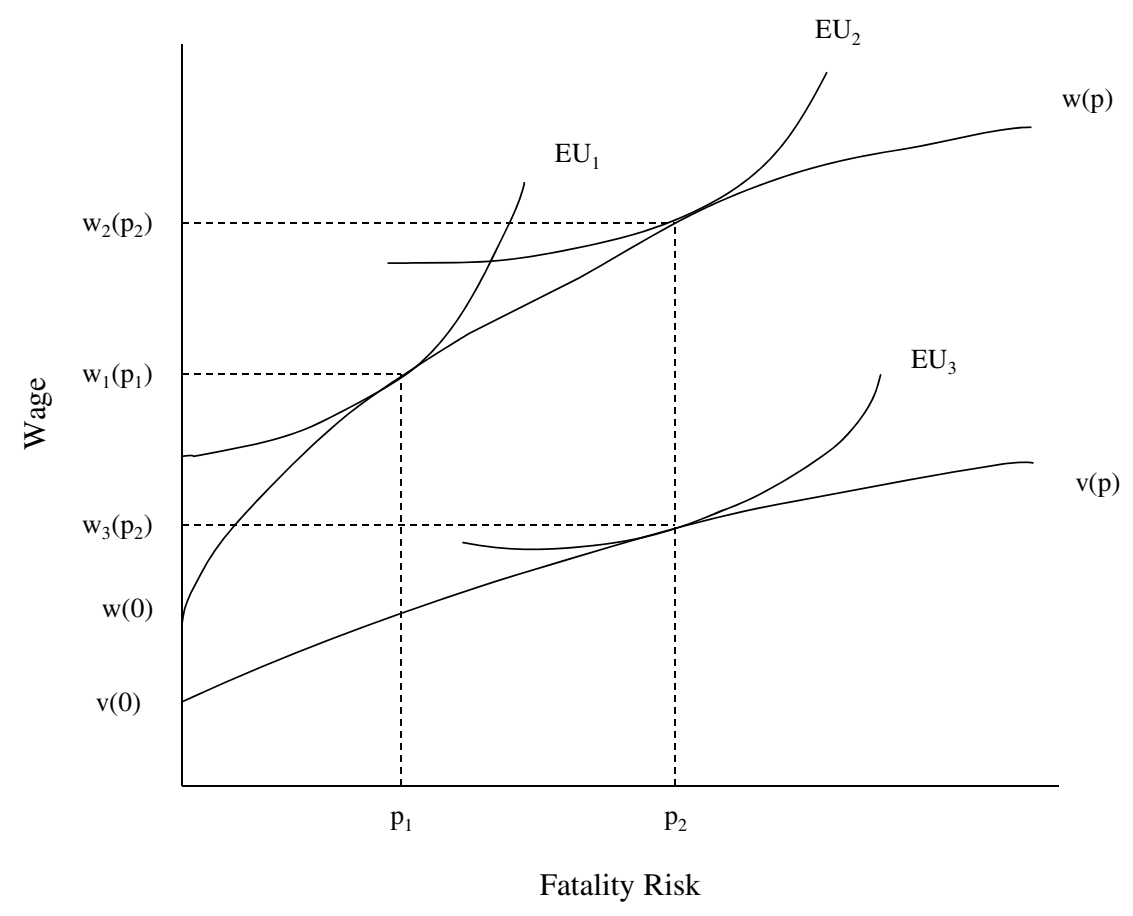

Fig. 4.1 The Viscusi-Hersch hedonic labor market model.

into positions along $w(p)$. Worker 3 does not have the option of choosing from this higher labor market offer curve and consequently must pick the best of available choices from $v(p)$. As indicated in the diagram, Worker 3 chooses a job risk $p_{2}$. However, that worker receives a lower wage compensation for that risk than does Worker 2, who chooses the same risk but from a more favorable labor market offer curve since $w(p)$ is steeper at $p_{2}$ than is $v(p)$. Thus, the difference $w_{3}\left(p_{2}\right)-v(0)$ shown in Figure 4.1 is smaller than the difference $w_{2}\left(p_{2}\right)-w(0)$. What matters from the standpoint of VSL differences is not the vertical intercept but whether the rate of tradeoff between money and risk also differs. Thus, is the slope of $v(p)$ flatter than that of $w(p)$, as indicated in the diagram?

In general we do not estimate all the different points along the curve and compare them, but rather we obtain an average VSL number for a particular sample. Suppose that one group of workers facing an average 
risk $p_{2}$ receives a wage rate of $w_{2}\left(p_{2}\right)$. Then that worker's compensating wage differential for the risk $p_{2}$ is given by $w_{2}\left(p_{2}\right)-w(0)$ and is shown in Figure 4.1. In contrast, the workers who pick off the lower offer curve on average receive a wage $w_{3}\left(p_{2}\right)$ for the risk $p_{2}$ and consequently earn an average compensating wage differential $w_{3}\left(p_{2}\right)-v(0)$. If workers face identical average risks but receive higher total compensating wage differentials for risk than does another worker group, then we can conclude that they are on a different wage offer curve. A stronger version of this test is to compare workers at different risk levels. In particular, if one worker group faces a lower risk $p_{1}$, then their total compensating differential for that risk should be lower than that for a worker group that faces a higher risk $p_{2}$. If this does not hold, then it clearly contradicts the assumption that the workers are on the same labor market offer curve.

To date there have been three studies that have analyzed whether there are segmented labor markets from the standpoint of compensating wage differentials for risk. The first of these studies was Viscusi and Hersch (2001), which focused on the difference between smokers and nonsmokers. Because smokers incur substantial personal risks as a consequence of their smoking behavior, one would expect them to be willing to accept job risks for a lower wage premium than nonsmokers and to gravitate to the higher risk, low wage-risk tradeoff jobs. Whether smokers will simply be located further to the right on the flatter portion of the market offer curve than nonsmokers or whether they will be on different labor market offer curves is an empirical issue. What they found in their analysis of job injury risks is that smokers faced higher risks on the job than did nonsmokers, but they received a lower wage premium for risk, providing evidence of different labor market offer curves facing smokers and nonsmokers. ${ }^{1}$

This issue of labor market segmentation also arises with respect to racial differences in compensation for risk. Viscusi (2003) analyzed the compensating differentials faced by black and white workers in the U.S. economy. While black workers faced greater risk than did whites,

\footnotetext{
${ }^{1}$ However, in a sequel, Viscusi and Hersch (2008) consider fatality risks rather than injury risks and do not find statistically significant differences between smokers' and nonsmokers' VSL amounts.
} 
they received lower wage premiums for risk. The same kind of procedure described above for testing for different labor market offer curves implied that the heterogeneity in the VSL levels observed across racial groups could be traced to different labor market opportunities that these groups faced.

A currently topical, policy-related example of this phenomenon is with respect to the labor market role of immigrant workers. In particular, it is often suggested that recent immigrants perform the least attractive jobs in the economy that nonimmigrant American workers are unwilling to do. Translated into economic terms, such statements imply that these immigrants have different rates of tradeoff between risk and wages than do native U.S. workers. However, the welfare implications of these differences are quite different if immigrant workers face different and less attractive wage offer curves than do native U.S. workers rather than selecting jobs from similar market offer curves.

The potential importance of such heterogeneity is the focus of the recent article by Hersch and Viscusi (2010a). Their analysis considered a comprehensive set of U.S. immigrant groups. Notably, immigrants in general often did not differ from native U.S. workers in terms of the risk premiums they received. However, Mexican immigrants, particularly those who lacked English language skills, fared particularly poorly in the labor market.

Table 4.1 summarizes some of their results with respect to native U.S. workers as compared to Mexican immigrants. The first set of

Table 4.1. Value of statistical life and immigrant status.

\begin{tabular}{lcc}
\hline & Fatality risk $^{\mathrm{a}}$ & VSL $(\$ 2003$, millions $)$ \\
\hline Estimates Based on the Current Population Survey $(C P S)$ & \\
Native U.S. & 4.35 & 7.95 \\
Mexican immigrants & 5.97 & Not statistically significant \\
& \\
Estimates Based on the New Immigrant Survey $(N I S)$ & \\
All immigrants & 4.50 & 9.35 \\
Mexican immigrants & 5.70 & Not statistically significant \\
Mexican immigrants who speak English & 5.70 & 3.44 \\
\hline
\end{tabular}

Source: Data are from Hersch and Viscusi (2010a).

${ }^{a}$ Fatality risk is by industry-immigrant status-age using Census of Fatal Occupational Injuries (CFOI) data. Fatality risk is annual fatality rate per 100,000 workers. 
results in Table 4.1 consists of estimates derived from the Current Population Survey (CPS). As indicated, Mexican immigrants face an average fatality risk on the job that is almost one and a half times that of native U.S. workers. These fatality rate estimates are calculated using the Census of Fatal Occupational Injuries (CFOI) data conditional on the worker's industry, immigrant status, and age. Native U.S. workers receive wage compensation for risk that implies a VSL of $\$ 7.95$ million. However, the fatality risk variable is not statistically significant in the log wage equation for Mexican immigrants, indicating that they do not receive statistically significant compensation for risk. Taken together, these results provide evidence of labor market segmentation as hypothesized in Figure 4.1.

A somewhat different comparison is provided in the lower panel in Table 4.1 in which all immigrants are compared to Mexican immigrants using data from the New Immigrant Survey (NIS). Immigrants generally face a risk level similar to that of native U.S. workers and, based on the results from this study, have an average VSL of $\$ 9.35$ million. However, Mexican immigrants once again face a much higher risk level and do not receive statistically significant compensation for the risk.

What these results indicate is that in analyses that seek to identify different types of heterogeneity in the VSL tradeoffs in the labor market, it is essential to ascertain whether the groups do in fact face similar labor market offer curves. How one interprets the observed heterogeneity in estimated VSL levels is quite different if the estimated VSL is derived from selecting a different point from a particular wage offer curve as opposed to the worker being relegated to a less attractive set of labor market opportunities with different available wage-risk tradeoffs. If the differences in labor market opportunities arise from influences such as discrimination, then whether and how one would choose to use the estimated labor market estimates of VSL based on the estimates across different groups will be affected as well.

Consequently, in instances of segmented labor markets there should be further probing of the causes of differences in labor market opportunities before incorporating the implications of any such heterogeneity in policy assessments. One possible source of evidence is to use the results of stated preference surveys or market-based imputations of VSL based 
on other choices not affected by labor market segmentation, such as the price premium these groups are willing to pay for safer motor vehicles.

Not all individual differences lead to segmented labor markets. One such case may be differences by gender. Women tend to face low job fatality risks, making estimation of gender-specific VSL difficult. ${ }^{2}$ However, in an analysis of overall job injury risks, Hersch (1998) found that female workers faced substantial hazards and also received significant compensating differentials for risk.

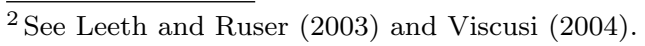




\section{Heterogeneity Based on Age}

The VSL varies with individual age because the length of the remaining life decreases with age, thus affecting the magnitude of what is at risk. Expenditures to reduce the risk of death extend life expectancy but do not lead to immortality. How the role of age influences the VSL depends on various life-cycle effects. Changes in individual wealth and family commitments over the life cycle affect one's willingness to pay (WTP) for risk reductions. In part, this life-cycle dependence of VSL arises from imperfect capital markets that prevent people from borrowing and lending money across time and from the inability to purchase life insurance at actuarially fair rates. If we could draw on our expected future lifetime earnings at birth, matters would be quite different. Such a prospect for borrowing on future income would also create severe moral hazard problems so that not offering this arrangement is not an oversight by the insurance industry.

For over two decades, there have been numerous labor market studies of age differences and VSL. In the early studies in the literature, the initial approach was to include in the wage equation an interaction term of the fatality risk and the age variable. My series of studies with Moore, such as Moore and Viscusi (1988b), include examples of this 
approach. Although the simplest models include only an age-fatality risk interaction, other formulations that were estimated included the expected life years lost based on the job risk and the worker's age. Thus, the models jointly estimated the worker's rate of time preference and the VSL. Some of these articles estimated various structural hedonic models in Moore and Viscusi (1988b, 1990a,b) and Viscusi and Moore (1989). The estimates based on these studies often yielded rates of time preference that were sometimes in the $20 \%$ range, perhaps because the studies used death risk data by industry and did not account for age differences in risk. Age-specific fatality rates could not be constructed using data available at that time.

While these studies found an average rate of time preference across the labor market, this value depends on the worker group. Scharff and Viscusi (2009) found that workers who are smokers have a much higher rate of time preference with respect to years of life than do nonsmokers based on estimates of the wage premiums for risk and workers' average implicit rates of time preference.

The recent spate of studies of the age-VSL relationship has been enhanced by the availability of better job fatality data. The fatality risk variable in early studies of age and VSL was not age-specific because such data were not available. As a result, the degree of refinement that was permitted by the data did not extend beyond estimating an average value per statistical life year, based on the assumption that all workers in an industry faced the same risk and all discounted years of life are equally valued. More recent studies of the influence of age have taken advantage of the additional refinement made possible by use of the CFOI data. Using these data, which provide a comprehensive inventory of all U.S. job-related fatalities, it is possible to construct age-specific risk measures by industry, occupation, and other matters of interest. The result of wage equation estimates using these measures is that the age-VSL relationship reflects an inverted-U shaped pattern. ${ }^{1}$ However, this shape is not symmetric as the upturn at early ages is steeper than the downturn at later ages. This overall shape is consistent with the implications of theoretical models in which the life-cycle pattern of VSL

${ }^{1}$ See Smith et al. (2004), Viscusi and Aldy (2007), and Aldy and Viscusi (2007, 2008). 
is estimated based on an assumption of imperfect capital markets, as in Shepard and Zeckhauser (1984).

Because of the role of imperfect capital markets, the life-cycle pattern of income is instrumental in influencing the value of VSL at different age groups. In particular, the estimated VSL is flatter if one controls for consumption over the life cycle or for cohort effects. The pivotal role of life-cycle effects is borne out as the VSL shape over workers' lifetimes tracks the lifetime income and lifetime consumption profiles quite closely, as demonstrated in Kniesner et al. (2006), who use the Panel Study of Income Dynamics (PSID) in conjunction with CFOI data.

The age variation in VSL is shown in Figure 5.1, which presents estimates of the VSL by age group from Aldy and Viscusi (2008), who use the CPS in conjunction with CFOI fatality rate data, which was used to construct fatality rates by industry and age. The bold curve indicates the cross-sectional estimates of VSL, whereas the dashed line adjusts the VSL estimates, taking into account the particular cohort that the individual is in. As is indicated, the cohort-adjusted VSL is lower for younger age groups and higher for older age groups, reflecting the fact that those in older age groups are from an earlier labor market

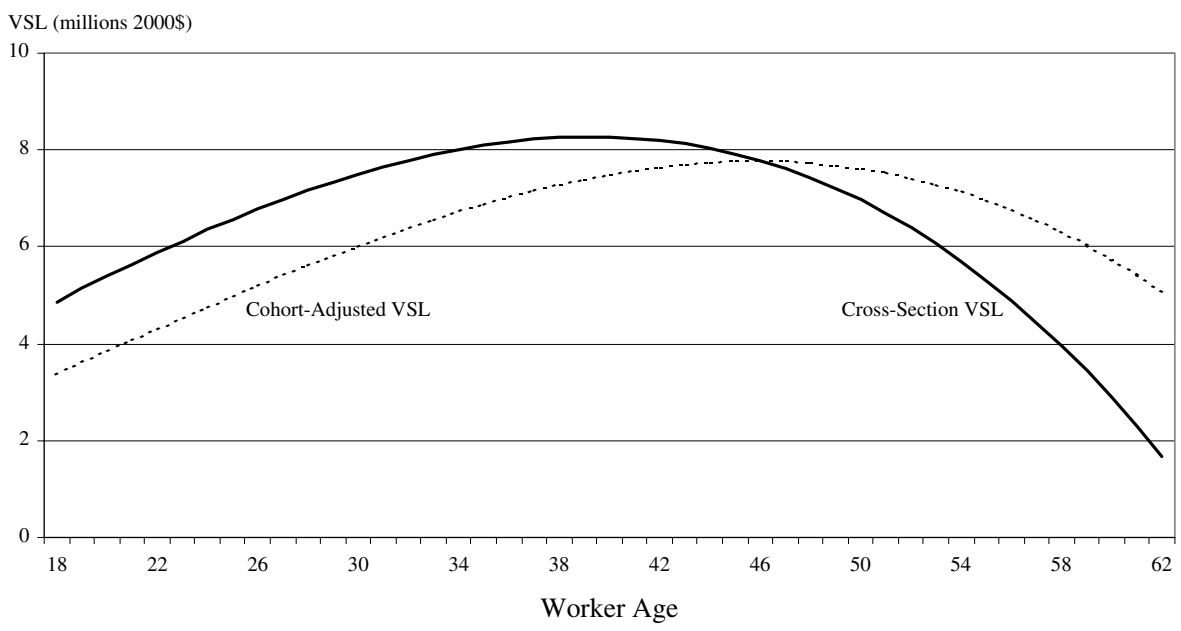

Fig. 5.1 Cohort-adjusted and cross-section value of statistical life, 1993-2000. Source: Aldy and Viscusi (2008). 
cohort. The peak estimate for the VSL for that study is just under $\$ 8$ million in the cohort-adjusted estimates and occurs around age 50.

To summarize, what do we know about the age-VSL relationship based on the labor market evidence ${ }^{2}$ First, the VSL does not peak at birth as would be the case if all that mattered is the total remaining life expectancy. Second, the VSL does not plummet steadily as we age. Notably, the VSL for workers around age 60 in Figure 5.1 is higher than the VSL for workers around age 20. This result is not unique to this particular study but rather is the norm in recent labor market analyses of VSL, as in the study by Viscusi and Aldy (2007) and the review of such studies by Aldy and Viscusi (2007). In particular, the VSL represents the individual's personal wage-risk tradeoff, which in turn will be affected by one's resources at that particular stage in the life cycle. The total remaining life expectancy alone is not the sole factor influencing the VSL estimate.

Recently economists have begun to explore the valuation of lives outside of the labor market age range. Children are a prominent example, where these valuations are derived from stated preference studies of parents and other adults. Examples of such analyses are Hammitt and Haninger (2010) and Blomquist et al. (2011).

\footnotetext{
$\overline{2}$ The stated preference evidence on the age-VSL relationship is reviewed by Krupnick (2007) and indicates a less pronounced pattern of age and VSL.
} 


\section{6}

\section{Value of a Statistical Life Year (VSLY)}

\subsection{The VSLY Approach}

In many contexts, such as those involving regulations that affect people with very short remaining life expectancy, it is not appropriate to use the standard VSL measure. Rather, taking into account the difference in longevity often leads to the use of the VSLY. The basic formula for this method developed in Moore and Viscusi (1988b) divides the VSL estimate by the discounted expected remaining years of life to obtain the valuation per discounted expected life year. Their "quantityadjusted value of life" approach gave rise to what is now termed the VSLY concept.

Although Moore and Viscusi present the VSLY formula in continuous time, it is also instructive and simpler to consider the discrete time analog. Let $r$ equal the worker's rate of interest used in discounting years of life and $L$ indicate the worker's remaining life expectancy. Then, assuming a time-invariant value of VSLY in each year,

$$
\mathrm{VSL}=\frac{\mathrm{VSLY}}{r}-\frac{1}{(1+r)^{L}}\left[\frac{\mathrm{VSLY}}{r}\right]
$$


or VSL equals the value of VSLY over an infinite remaining future lifetime minus the value of life years beyond one's future life expectancy. Solving Equation 6.1 for VSLY yields

$$
\mathrm{VSLY}=\frac{r \mathrm{VSL}}{\left[1-(1+r)^{-L}\right]}
$$

Formulations such as this have been used to estimate an average VSLY implied by VSL estimates coupled with values of $L$ and estimates of $r .^{1}$

Whereas that article and several sequels have assumed a constant valuation per year of life, the advent of more refined fatality risk data makes it possible to construct measures of the industry and/or occupational fatality rate for workers of different ages, greatly expanding the kinds of analyses that can be undertaken. Viscusi and Aldy (2007), Aldy and Viscusi (2008), and Viscusi and Hersch (2008) analyze VSL and VSLY by age using a job fatality rate measure that is specific to the worker's industry as well as the worker's age group. The estimates derived from this approach imply that VSLY is not a constant and is not steadily declining with age even though individual health may decline. Rather, the VSLY rises fairly steadily before eventually tapering off.

Figure 6.1 presents one such set of estimates from Aldy and Viscusi (2008) using the CPS. Consider the cohort-adjusted VSLY estimates indicated by the dashed lines in the figure. The VSLY rises from about $\$ 125,000$ for those in their late teens and reaches a peak of about $\$ 400,000$ around age 54 . Thereafter, the VSLY tapers off but nevertheless remains quite substantial, at a level of $\$ 350,000$ for workers age 62 . These results, in conjunction with those in Figure 5.1 for VSL, indicate why the VSL does not plummet with age. Over the life cycle there is a substantial rise in the valuation that people place on each year of life. The source of this time variation can be traced to life-cycle changes in income and consumption, which are examined below.

\footnotetext{
${ }^{1}$ For a recent review of the VSLY literature see Hammitt (2007).
} 


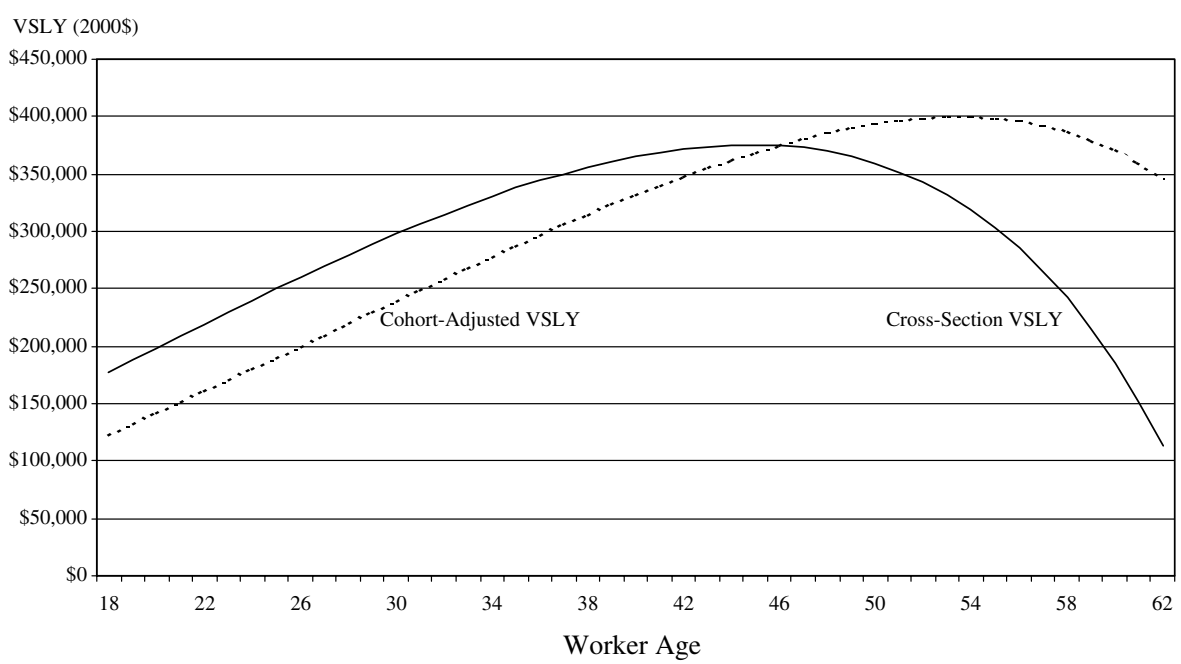

Fig. 6.1 Value of a statistical life-year based on cohort-adjusted and cross-section value of statistical life, 1993-2000.

Source: Aldy and Viscusi (2008).

\subsection{An Application of VSL and VSLY to the Private Cost of Cigarettes}

The VSL and VSLY estimates can be used in policy analyses in a variety of contexts. An illustrative application is that in Viscusi and Hersch (2008), in which they estimate the VSL and VSLY specific to the individual's smoking status. ${ }^{2}$ Using the estimated VSL and VSLY statistics for smokers and the associated lost life expectancy with smoking, they calculate the private mortality cost per pack of cigarettes. This calculation assumed that years of life in retirement age have the same value as years age $55-64$.

The value of the private mortality costs varies considerably depending on the rate of time preference and the VSL. At a 3\% rate of interest, the cost per pack is on the order of $\$ 200$ for men and $\$ 100$ for women. However, at smokers' estimated labor market discount rate for years of life at $14 \%$ (Scharff and Viscusi, 2009), the cost per pack drops to $\$ 24$ for men and $\$ 6$ for women. At even higher rates of interest, such as

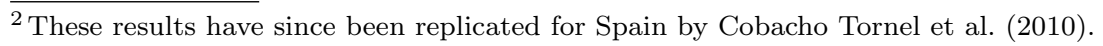


those revealed in the labor market risk decisions by blue-collar workers, the cost per pack decreases even further.

There are two key components pertinent to whether and to what degree these mortality costs reflect private costs for the smoker. The first component of interest is whether smokers fully understand the length of life that will be lost due to smoking. Male smokers estimate the life expectancy loss due to smoking as 8.6 years, and female smokers estimate the loss at 13.2 years, each of which far exceeds the actual estimated life expectancy loss. ${ }^{3}$ Thus, the perceived mortality effect is quite large. However, the second component of the smoker's calculation is the rate of time preference for years of life, which smokers have shown through their job choices to be far higher than $3 \%$. The presence of a high rate of discount in conjunction with the high life expectancy loss figures account for why smoking is nevertheless attractive to smokers. What these calculations also demonstrate is that the main cost associated with cigarettes is the health loss to smokers, not the financial externalities associated with smoking, which on balance are negative. Even the positive financial externality components such as medical costs due to smoking are under $\$ 1$ per pack. Thus, these calculations of the costs per pack provide no new information for smokers, who already overestimate the mortality risk and life expectancy loss of smoking. Rather, they translate the estimated life expectancy loss into economic terms. ${ }^{4}$

\footnotetext{
${ }^{3}$ See Viscusi (2002), p. 148.

${ }^{4}$ See Viscusi (2002) for a review of the financial externalities of smoking as well as smokers' risk beliefs.
} 


\section{Income Effects}

Compensatory damages for wrongful death include as a standard component compensation for the present value of the lost earnings that the family experiences because of the death. While there may be adjustments for taxes and consumption, depending on the particular state law, the net result is that this component of compensatory damages is proportional to the value of the income that is lost. In much the same way, the WTP to decrease fatality risks is also likely to increase with one's income given that one's health is a normal good. The main empirical issue is how great the responsiveness is to the level of income.

The positive relationship between income and VSL is well established both theoretically and empirically. The positive linkage was first analyzed and estimated in Viscusi (1978b), who found the predicted positive relationship. This relationship in turn spawned a series of studies of the effect of inordinately large regulatory expenditures on the lives lost through the opportunity costs of these expenditures. ${ }^{1}$

More recently, there have been attempts to link the income elasticity of VSL to measures of financial risk aversion in order to establish

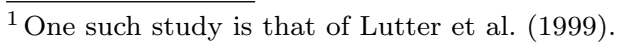


numerical estimates of the likely income elasticity range of VSL. Kaplow (2005) has developed a model whereby VSL must be income elastic for the VSL estimates to be consistent with existing estimates of the coefficient of relative risk aversion. However, it should be noted that the empirical evidence on risk aversion measures is quite sparse. Eeckhoudt and Hammitt (2001) and Evans and Smith (2010) develop similar models, but the relaxation of Kaplow's assumptions by Evans and Smith makes the theoretical relationships less clearcut. Resolving the magnitude of the income elasticity of VSL is an empirical question.

There have been two principal estimation strategies that have been used to assess the income elasticity of the VSL. The first consists of meta analyses across different VSL studies. The meta-analysis approach estimates the income elasticity based on how the VSL responds to differences in the wage level in the studies. The component VSL values are average estimates across each particular sample and consequently do not reflect the full range of heterogeneity within the sample.

The meta-analysis estimates by Viscusi and Aldy (2003) yield an elasticity estimate in the range of 0.51 to 0.61 . Their study used a series of ten different specifications that spanned all the possibilities that have been considered in the previous VSL meta-analysis literature by Liu et al. (1997), Miller (2000), Mrozek and Taylor (2002), and Bowland and Beghin (2001). The estimates were not greatly sensitive to the specification used.

An alternative approach to estimating the income elasticity of VSL is to use quantile regression estimates within a single sample to analyze how the VSL for workers at different wage levels differs depending on the level of the fatality risk. A much more substantial estimate of the income elasticity is reported in Kniesner et al. (2010), who use quantile estimates using the PSID data on worker wages in conjunction with CFOI fatality risk data by industry and age. They estimate a mean income elasticity across the different quantiles of 1.44. As shown in Table 3.1, the income elasticity varies substantially across the working population and across the different wage and income levels in the population.

Although the equation specification used in this study parallels that of a standard hedonic wage analysis, the resulting estimate of the 
income elasticity is quite different than that implied by meta analyses. One possible explanation is that meta analyses may suppress evidence of some income elasticity across the population because their focus is on differences in the average VSL across studies, which does not fully account for the within-study heterogeneity that is evident in the quantile analysis. Notwithstanding these differences in the magnitude of the income elasticity, it is clear that the value of the income elasticity of VSL is positive and substantial.

The influential role of the positive income elasticity of VSL also has ramifications for the age variations in VSL. Kniesner et al. (2006) find that life-cycle consumption patterns are strong predictors of the level of VSL. Indeed, the trajectory of VSL over the life cycle mirrors the trajectory of life-cycle consumption. The strong income elasticity of VSL at any point in time consequently has a powerful influence in contributing to the observed life-cycle pattern of VSL. 


\section{The Advent of Using VSL in the Policy Arena}

Although policy makers were initially reluctant to adopt the VSL approach, this methodology has now become standard practice for agencies in performing their regulatory analyses of risk regulations. There have also been policy implications involving age adjustments and income adjustments to VSL, and it is useful to explore how these variations have been treated in policy assessments.

Before the advent of the use of the VSL methodology to value risks to life in regulatory impact analyses, the government nevertheless did attach a finite benefit value to these losses. Typically the approach parallels that used in personal injury cases based on the present value of lost earnings and medical costs. In its 1992 assessment of a proposed hazard communication regulation, the Occupational Safety and Health Administration (OSHA) suggested that this human capital benefit measure in fact calculated the "cost of death," which the agency regarded as less controversial than using the value of life methodology because in its view, life is too sacred to value. After reviewing OSHA's regulatory impact analysis of its proposed hazard communication regulation, the Office of Management and Budget (OMB) concluded that 
the benefits did not exceed the costs. As a result, OMB rejected the regulatory proposal.

OSHA then appealed the OMB decision to then Vice-President Bush. I was asked to resolve the dispute between the two agencies by analyzing the merits of the proposal as well as the OMB critique of it. By using my estimates of the value of life, which has since been termed the VSL, I showed that the benefits exceeded the costs. In particular, use of my VSL estimates increase the value of the estimated benefits by a factor of ten. ${ }^{1}$ As a result of this analysis, the regulation became attractive on benefit-cost grounds. Calculated benefits now exceeded the value of costs, and the day after the White House received my report in support of the regulation, the regulation was issued.

What is particularly noteworthy about this case study is that in this historical context, use of the VSL estimates approach was more supportive of risk regulation than making lives "priceless." Somewhat surprisingly, the VSL methodology is now under attack for pricing lives. However, at the time the VSL methodology was adopted the main critique was not that the lives were being priced at too low an amount but rather that the number was so large and so far in excess of the present value of lost earnings that many questioned whether it was a reasonable basis for benefit assessment.

${ }^{1}$ My 1982 estimates used in this analysis were just over $\$ 3$ million per expected life saved. See Viscusi (1992) for further presentation of the analysis. 
9

\section{The "Senior Discount" Controversy}

Although empirical evidence indicates that there are age variations in VSL, whether and how these age variations should be taken into account for purposes of benefit assessment are controversial. In its analysis of the Clear Skies Initiative in 2002, the U.S. EPA (2002) used a senior discount of $37 \%$ in a benefits analysis sensitivity test. This senior discount estimate was based on survey studies in the United Kingdom by Jones-Lee et al. (1985) with respect to the public's valuation of deaths from railroad accidents. EPA's use of a lower valuation figure for the lives saved for people over 65 led to a political firestorm. Protesters adopted slogans such as "seniors on sale - $37 \%$ off." ${ }^{1}$ EPA subsequently backed off the approach. Although such demographic adjustments for age have evoked controversy with respect to regulatory analyses, such adjustments for age and a variety of other personal characteristics are the norm for calculating ex post compensation in personal injury and wrongful death cases.

\footnotetext{
${ }^{1}$ Representative news accounts are "EPA Drops Age-Based Cost Studies," New York Times, May 8, 2003; "EPA to Stop 'Death Discount' to Value New Regulations," Wall Street Journal, May 9, 2003; and "Under Fire, EPA Drops the "Senior Death Discount,'" Washington Post, May 13, 2003.
} 
The controversy over age adjustments did not abate even after EPA abandoned this approach. Subsequently, Senator Barbara Boxer proposed legislation banning all demographic adjustments to VSL. It is important to note that this proposed prohibition against demographic adjustments for differences in the VSL only pertained to differences at a point in time rather than adjustments over time. Notably, under this proposed legislation VSL would have been required to increase over time as income levels rose.

Although there appears to be considerable resistance in the United States for any downward adjustments to VSL based on age, is not the case in other countries. As indicated previously there are international precedents for such policies in both Canada and the European Union. Canada has used a VSL that is $25 \%$ lower for those over 65 compared to those under 65, and in 2001 the European Commission recommended that the VSL measure should have a declining value with individual age.

While VSL estimates do not plummet with age, there are clearly age-related variations in VSL. Moreover, use of age-specific VSL measures in some instances may boost the values placed on those who are older as they have higher VSL amounts than do workers at the other end of the age spectrum. Unfortunately, labor market evidence does not provide information on the VSL magnitudes for those outside of the labor market at both extremes of the age spectrum.

Suppose that to avoid controversy the objective is to value policies based on fairness instead of using the efficiency-based measure of the VSL-age relationship. Adopting a fairness approach may not provide definitive guidance as it is not clear whether appeals to fairness would resolve the controversy. One way of posing the fairness question would be to ask whether using the same value per statistical life for all age groups is equitable. That approach appears to have some symmetry across different age groups and is certainly the kind of fairness approach that the opponents of the senior discount incident would favor. However, this approach places the same value on lives that are very short as on lives that are very long. Consequently, each year of life for older people is given a greater value than each year for younger people. Alternatively, one might pose the fairness question in terms 
of whether having the same value per statistical life year is equitable. Equalizing the VSLY across people is incompatible with using a uniform VSL number irrespective of a person's life expectancy. A constant VSL will create inequities by overvaluing the life years of those with very short remaining life expectancy.

Such appeals to fairness consequently do not resolve the choice of the appropriate age adjustment to VSL, as there are differing and quite legitimate perspectives on what is fair. The main guidance should be derived by returning to basic economic principles. In particular, the guiding principle for any age adjustment should be to ascertain the individual's WTP for the risk reduction. This WTP value does in fact vary with age and eventually declines with age. But the VSL is not a steadily decreasing function of age and does not plummet with age. 


\section{Should Income Levels Matter?}

While empirically there is a positive income elasticity of VSL, whether income level differences should be taken into account for purposes of regulatory analyses is seldom confronted by regulatory agencies. Use of a uniform VSL irrespective of the income group targeted by the policy will result in regulatory policies that the poor do not value given their particular wage-risk tradeoff. If the cost of the policy will in fact be shifted to this beneficiary group in some way, then from their vantage point they will be made worse off by using a VSL that exceeds their personal value.

A prominent example where the VSL-income relationship comes into play is with respect to airline safety. In particular, should we regulate airline safety more stringently than highway safety given that the passengers on airlines have a much higher income level than the average person killed in an automobile accident? In a study prepared for the Federal Aviation Administration (FAA) that was subsequently published as Viscusi (1993), I showed that, based on the respective income levels of those being protected and available income elasticity at the time, a higher VSL amount was pertinent for airplane fatalities than for guardrails. 
Although FAA did not adopt a positive income elasticity for VSL at that time due to opposition from other branches of the agency that regulated motor vehicles, matters changed in 2008. The U.S. Department of Transportation (2008) became the first government agency to formally adopt a positive income elasticity for VSL. Based on the Viscusi and Aldy (2003) income elasticity estimates, the agency selected an income elasticity value of 0.55 , which was the midpoint of their estimated income elasticity range. The U.S. Department of Transportation's proposed adjustment of the VSL based on income levels is a very bold policy initiative to account for within-population differences. If the U.S. Department of Transportation subsequently uses these higher numbers for valuing airline safety, then the rationale for doing so is more compelling than in most policy contexts because the beneficiaries of the safety regulation will bear the cost of the higher levels of safety mandated by more stringent regulations.

In contrast, income changes over time have received much more widespread support among federal agencies. In the nearer term, there might be income adjustments to account for the fact that society is gradually becoming more affluent, and the VSL numbers should be updated to reflect changes in societal income levels. For analyses pertaining to the more distant future, such as analyses of climate change policies or similarly remote environmental problems, the income changes involve future generations rather than those who are currently alive. Making adjustments for differences in income is efficient. However, upward adjustments for future benefit valuations will redistribute income from the poorer current generation to a more affluent future generation, which some may view as inequitable. In response, climate change adherents assert that global warming will make future generations worse off.

In their conceptualization of the proper role of income adjustments, policy makers often fall prey to reference dependence effects. The current VSL level serves as the reference point, and upward adjustments are viewed much more favorably than are decreases. Proposed Senate legislation in 2008 required that there be annual income adjustments 
for VSL based on changes in income. ${ }^{1}$ In keeping with this reference dependence bias, the proposed legislation also stipulated that only increases in VSL due to rises in income are permitted, and agencies are required to make such adjustments. Decreases in VSL if income levels decline are prohibited. Thus, even if there is a pertinent positive income elasticity of VSL and if income levels decline, perhaps because of severe economic downturns, then the higher VSL value from the more affluent period would be maintained. Similarly, improved economic studies indicating that VSL had previously been overestimated cannot be taken into account. There is no economic efficiency rationale for such an asymmetry.

Such attempts to constrain the benefit values based on the political acceptability of different kinds of benefit adjustments are inconsistent with the fundamental principles underlying benefit-cost analysis. The proper benefits measure should be grounded in the WTP of the beneficiaries of the policy. Whether these individual preferences indicate a positive income elasticity or other types of heterogeneity in preferences does not invalidate the importance of adhering to reliance on individuals' WTP for guidance in setting benefit levels. To impose constraints on income adjustments or any other aspects of the benefit assessment process in effect overrides individual preferences and the pivotal economic role of consumer sovereignty.

1 "Restoring the Value of Every American in Environmental Decisions Act," (proposed 110th Congress, 2nd Session). 


\section{The Devaluation of Life Controversy}

This kind of asymmetry in treating changes in the VSL amount is also manifested in the devaluation of life controversy that emerged in 2008 with respect to the EPA Office of Air Quality Planning and Standards' (OAQPS) change in the VSL figure used in its regulatory analyses. ${ }^{1}$ This branch of the EPA based its update of the VSL amount on the results of two meta analyses - Mrozek and Taylor (2002) and Viscusi and Aldy (2003). ${ }^{2}$ Based on its assessment of the implications of these analyses, the EPA Air Office lowered the VSL from $\$ 8$ million to $\$ 7$ million. From an external vantage point, this downward shift in the VSL presented an economic puzzle since income levels had risen since the time that OAQPS had selected its previous VSL level. Moreover, the agency did not articulate why the studies differed or whether the results of one of the studies were more credible and consequently should serve as the basis for selecting the VSL. The studies are not

\footnotetext{
${ }^{1}$ Viscusi (2009a) provides a comprehensive review of the controversy. The EPA SAB report just before 2008 by Cropper et al. (2007) deals with a variety of pertinent VSL issues.

${ }^{2}$ A subsequent meta analysis by Kochi et al. (2006) has also played a role in government agencies' deliberations.
} 
substitutes and take different approaches to their meta analysis. One of the principal differences between the studies is that the Viscusi and Aldy study used only the single best estimate of the VSL from each study. In contrast, Mrozek and Taylor used all reported estimates, which in some cases involved a very large number of different alternative econometric specifications based on the same underlying data. However, by including multiple estimates from each study, the Mrozek and Taylor analysis included observations that were not independent of one another. ${ }^{3}$ At the extreme, if one were to include the VSL estimates from all specifications reported in Viscusi (2004), then there would be 80 observations drawn from different specifications using a single data set.

Irrespective of the differences between the studies or whether the downward shift in the VSL is warranted, it is clear that in general agencies should have the freedom to reassess the scientific evidence pertaining to the VSL and make whatever adjustments they believe are appropriate even if doing so involves a decrease in the VSL. The public reaction to the decrease in the VSL was less sympathetic. Substantial political and public disapproval resulted as many suggested that this devaluation of life was a conspiracy on part of the Bush Administration to undermine regulatory policies. There is in fact no evidence that there was any broader policy intent as the decision to lower VSL was a decentralized decision within the EPA. Moreover, other branches of the EPA, such as the Office of Water, did not decrease the VSL that it used in its regulatory analyses. Ideally, if agencies have legitimate reasons to alter their VSL, they should be permitted to either raise or lower the value. The public furor that accompanied the devaluation controversy did not delve into the rationale for the change in the VSL figure, only with the direction of movement.

This devaluation of life controversy largely stimulated the draft Senate legislation in fall 2008 that proposed that agencies must only raise the VSL over time. What is particularly remarkable about this incident is that it is the change in the VSL that generated the controversy, not the level. Even with the downward adjustment to the VSL

$\overline{{ }^{3} \text { Their econometric }}$ analysis did include a clustering adjustment for the standard errors. 


\section{The Devaluation of Life Controversy}

figure, the OAQPS number for valuing risk to life was still relatively high compared to the value used by other federal regulatory agencies. For example, OAQPS was taken to task for decreasing the VSL to $\$ 7$ million even though that figure exceeded the U.S. Department of Transportation's VSL estimate at that time by more than $\$ 1$ million. 


\section{Adjustments for the Size of Risk}

\subsection{Risk Levels in Hedonic Wage Studies}

Government estimates of VSL are based on analyses of tradeoffs involving very small risks. The chief source of evidence is labor market studies, and these analyses pertain to risks that workers actually face rather than very large hypothetical risks. Other hedonic studies, such as those of housing markets and product markets, likewise are restricted to risk levels that are observable. Stated preference studies have no such limitation, but these analyses have generally focused on small risks as well. A common policy question that has received attention from the EPA Science Advisory Board and other agency groups is how these results might be extrapolated to quite different risk levels.

Suppose that we know the shape of $w(p)$ in Figure 12.1, or the locus of estimated, observed risk-wage combinations that workers find attractive. The market opportunities are generated by the offer curves of different firms, such as $\mathrm{OC}_{1}$ and $\mathrm{OC}_{2}$ in the diagram. Armed with the estimates of $w(p)$, what can we say about workers' willingness to accept jobs with much larger risks than the small risk levels considered in hedonic wage analyses? Consider Worker 1 who currently incurs a job

risk $p_{1}$ at firm 1 . If that risk level were increased to $p_{2}$, then applying the 


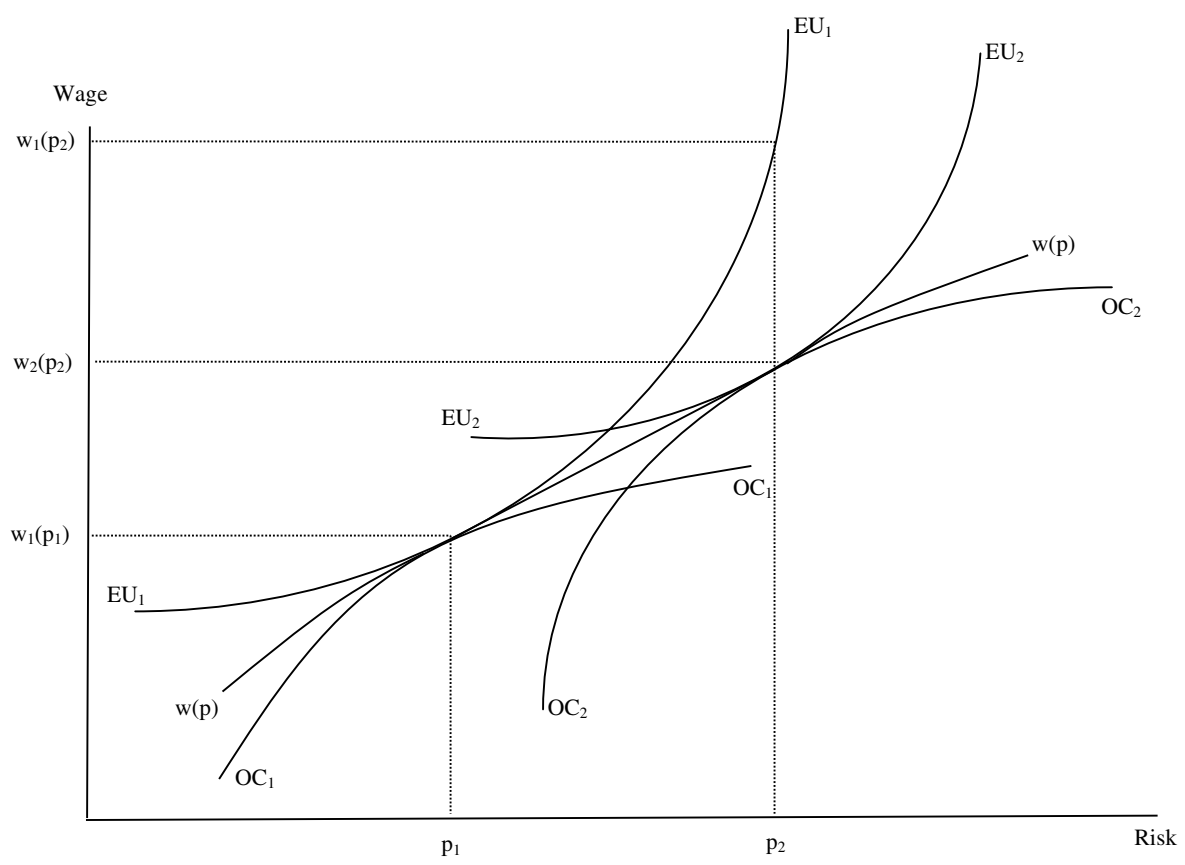

Fig. 12.1 Hedonic market equilibrium for fatality risks.

results from the hedonic wage function $w(p)$ would imply that Worker 1 would be willing to accept risk $p_{2}$ if the wage were increased to $w_{2}\left(p_{2}\right)$. However, that wage level will not keep Worker 1 on the same constant expected utility locus. A higher wage rate $w_{1}\left(p_{2}\right)$ is required, where this wage is necessarily greater than that implied by the hedonic wage analysis due to the curvature of $\mathrm{EU}_{1}$.

By similar argument, one can analyze the worker's WTP for large risk reductions below $p_{1}$. As a first approximation, one might wish to assume that the curve $w(p)$ approximates that value. However, as is shown in Figure 12.1, $\mathrm{EU}_{1}$ lies above $w(p)$ for risk levels smaller than $p_{1}$ so that the WTP values (or the drop in wages that workers are willing to accept) for substantial decreases in fatality risk will be less than those implied by the hedonic wage function.

Hedonic labor market studies of fatality risks of different magnitudes will capture two sets of influences. First, because such wage studies focus on willingness-to-accept (WTA) values for risk, as the risk levels 


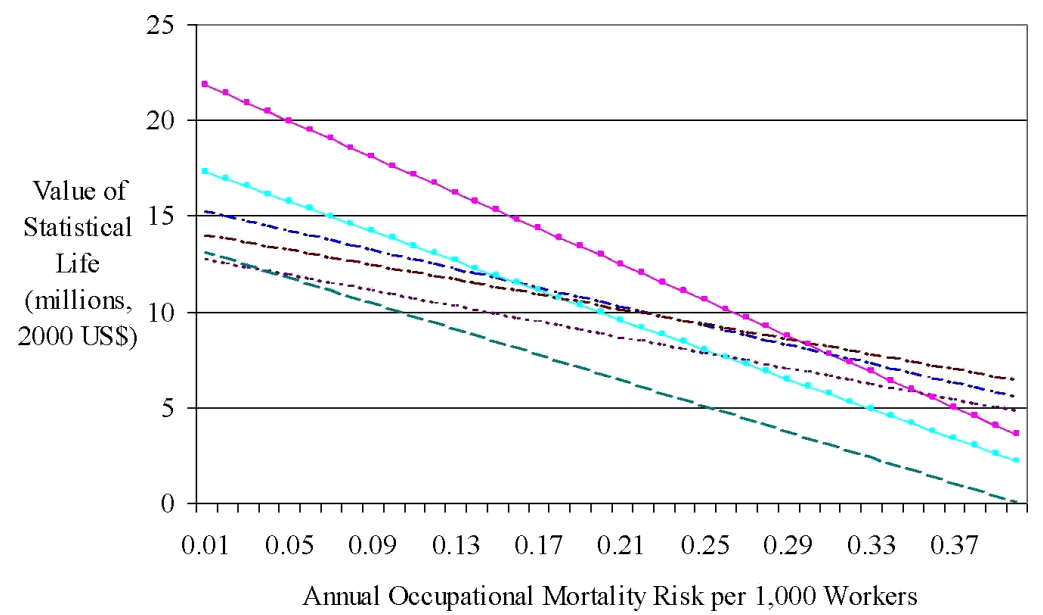

Fig. 12.2 Relationship of value of statistical life to risk level in hedonic wage studies. Source: Viscusi and Aldy (2003) based on six different studies of the relation of VSL to the level of the risk.

become very large the wage-risk tradeoffs should increase as well for any given worker. Second, people will sort in the labor market based on their risk preferences, and the workers who are in very high risk jobs have different preferences than those in more modest risk jobs. Workers who self-select into high risk positions will tend to have lower VSL values for any given risk level.

Figure 12.2 presents the Viscusi and Aldy (2003) results for the VSL-risk relationship from six different hedonic wage studies that included a quadratic risk term to capture the curvature of the $w(p)$ locus. Although the steepness of the decline in VSL with risk levels varies with the particular study, in every instance there is a downward sloping relationship. The dominant empirical influence is the sorting of people with lower VSLs into high risk jobs. These $w(p)$ curvature results consequently provide little insight into any particular individual's willingness to accept large risk increases or their willingness to pay for large risk decreases because the main factor driving market evidence on the variation of VSL with risk levels is the influence of individual sorting based on risk preferences, not changes in any particular individual's VSL tradeoff along a constant expected utility locus. Put somewhat differently, these estimates capture the shape of the market offer curve 
rather than the shape of an individual's constant expected utility locus. Government agencies looking for guidance in valuing major shifts in risk levels will have to rely on information beyond that conveyed by the hedonic wage estimates.

The risk levels analyzed in the hedonic wage studies have varied over time, in part because the workplace has become safer. ${ }^{1}$ The meaningful risk measures are those that attempt to isolate the risk associated with the worker's particular job. ${ }^{2}$ The first such measures were those based on the early U.S. Bureau of Labor Statistics (BLS) fatality risk data by industry. The early BLS data are based on a sample of firms that reported fatality statistics voluntarily. These risk data imply an average risk level on the order of $1 / 10,000$ for the time period beginning in the 1970s. The next wave of studies used data that were believed to be a more comprehensive tally of workplace fatalities. The National Institute of Occupational Safety and Health developed the National Traumatic Occupational Fatality (NTOF) data, which reduced the amount of measurement error in the fatality variable. Notwithstanding the name of the data set, the information is available by industry and by state, but not by occupation. The average risk levels in studies using these data are from $1 / 10,000$ to $4 / 10,000$. Estimates using these data roughly doubled the labor market estimates of VSL (Moore and Viscusi, 1988a).

The current gold standard for fatality risk data is the U.S. BLS CFOI. This data base consists of a complete census of all occupational fatalities rather than a sample. Each fatality is verified with multiple source documents, with four being the average number of sources used. The confidential micro data files can be used to construct risk measures by industry, occupation, industry-occupation, age, gender,

\footnotetext{
${ }^{1}$ Risk levels have also changed due to changes in job fatality data. The accuracy of these data affect the influence of measurement error, which is explored in Moore and Viscusi (1988a) and Black and Kniesner (2003).

2 The highest risk levels analyzed in the literature were in early studies that used the risk information from the Society of Actuaries, for which the average annual risk of fatality is $1 / 1,000$. These risk values are available by broad occupational group, but not by industry. The large risk value is misleading, however, as the data do not distinguish the occupationspecific risk but rather reflect the overall mortality risk from all causes associated with people in particular occupations. For example, in these data, actors have a particularly high risk, which is a reflection of their low income levels rather than any high job-related risk.
} 
race, immigrant status, or other matters of interest. The average annual fatality risk level in the studies using these data is about $1 / 25,000$.

While there are exceptions, for the most part the hedonic wage literature has focused on WTA amounts for job risk levels averaging from $1 / 25,000$ to $4 / 10,000$. By most standards, these are comparatively small risks. For such small risk changes, the WTP amounts for EPA benefit assessment should be fairly similar to the WTA amounts. As indicated with respect to Figure 12.1, for larger nonincremental risk changes, the estimated VSL from labor market studies will overstate the implied VSL based on WTP amounts and understate the implied VSL based on WTA amounts for large risk changes.

\subsection{A Calibration Example for Non-Incremental Risk Changes}

If we have information on the shape of individual utility functions, it is possible to analyze how the WTP amounts and WTA amounts vary depending on the magnitude of the risk change. We begin with the general formulation for VSL and then consider specific functional forms. Let $u(y)$ be the utility function of income $y$ when healthy, and let $p$ be the probability of death. For simplicity, suppose that bequests have a value of zero. Then VSL is given by

$$
\mathrm{VSL}=u(y) /\left[(1-p) u^{\prime}(y)\right] .
$$

Suppose that the utility function takes a logarithmic form $u(y)=$ $a+\ln (y)$. Such utility functions are specified up to a positive linear transformation, but the parameters must be set to be consistent with the estimated VSL. Assume that VSL $=\$ 7$ million and that the worker faces an annual fatality risk of $1 / 10,000$. Also let the value of $y=\$ 27,200$, which is roughly the current average annual wage income of blue-collar workers in the CPS. This information is sufficient to pin down the shape of the utility function.

Consider an order of magnitude increase in the size of the risk from $1 / 10,000$ to $1 / 1,000$. The associated risk change is $9 / 10,000$. Based on a VSL of $\$ 7$ million, the estimated WTA amount would be $\$ 6,300$. But to keep the worker on the same constant expected utility locus, the 


\section{Adjustments for the Size of Risk}

required WTA is $\$ 6,966$. Thus, the WTA is about 10 percent greater than would be predicted based on the local rate of tradeoff implied by the VSL. Similarly, the implied VSL for the discontinuous change in the risk level by $9 / 10,000$ is greater as well. The additional required wage compensation implies a VSL of $\$ 7.7$ million based on the WTA amount. Large risk increases consequently generate a WTA value greater than that implied by the estimated VSL from local tradeoffs, but the changes in the valuations are not stark within this particular range.

Government policies generally involve WTP amounts for decreases in risk rather than WTA values for risk increases. Suppose the starting annual fatality risk is $1 / 1,000$, the starting income is $\$ 27,200$, and the VSL based on local wage-risk tradeoffs is $\$ 7$ million. Suppose the risk is reduced to $1 / 10,000$ so that there is a risk decrease of 9/10,000. Based on an extrapolation from the estimated VSL, such a change would have an associated WTP amount of $\$ 6,300$. However, based on the WTP amount that will put the worker on the same constant expected utility locus, the WTP value is $\$ 5,825$, which is 8 percent less than would be predicted by the local tradeoff rate derived from the hedonic wage relationship. The estimated VSL associated with this nonincremental risk change is $\$ 6.5$ million.

Large risk changes consequently have a different associated VSL than implied by local rates of tradeoff, but the differences do not appear to be stark. The implied VSL amounts for these shifts are greater than the locally estimated VSLs from a WTA perspective and less than locally estimated VSLs from a WTP perspective. For the risk change amounts of 9/10,000 considered here, the WTA values were $10 \%$ greater than predicted, and the WTP amounts were $8 \%$ lower than predicted. That the discrepancy should be greater for the WTA amounts is expected given the curvature of the constant expected utility locus. As can be seen from Figure 12.1, the curvature of $\mathrm{EU}_{1}$ ensures that the WTP-magnitude of risk change relationship will be on a flatter portion of the $\mathrm{EU}_{1}$ than the WTA-magnitude of risk change relationship. Thus, to the extent that agencies are largely concerned with WTP estimates more than WTA values, the change in the rate of money-risk tradeoffs with large changes in risk is less than would be the case for WTA values. 


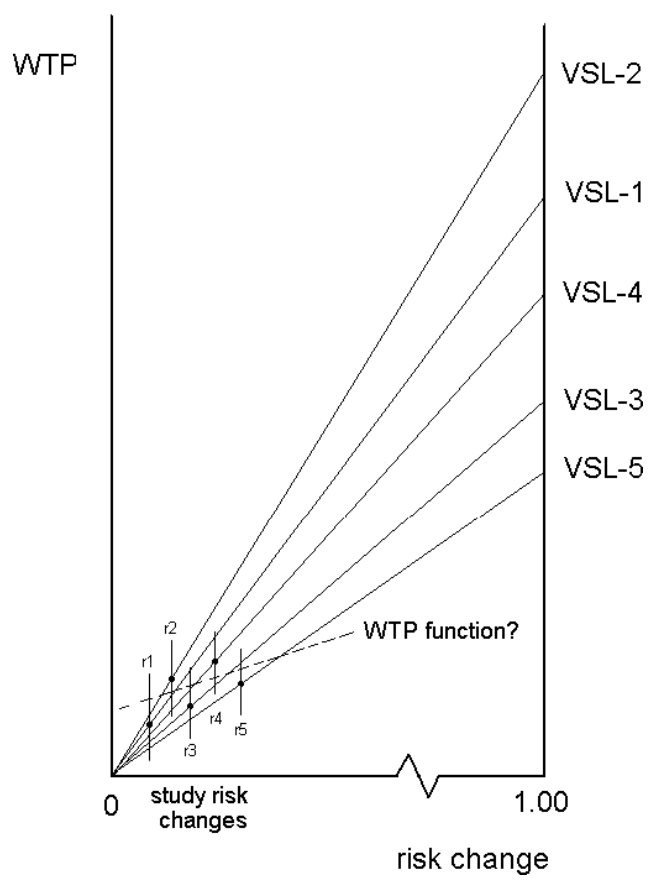

Fig. 12.3 Illustrative analysis of meta analyses.

An interesting application of the concern with the size of the risk change is with respect to a VSL diagram that appeared in Appendix D of the Review of the Revised Analytical Plan for EPA's Second Prospective Analysis - Benefits and Costs of the Clean Air Act 1990-2020, Draft report, No. EPA-SABCOUNCIL-ACV-XXX-XX, March 5, 2004. Figure 12.3 is drawn from that report. The risk-WTP combinations $r_{1}$ through $r_{5}$ indicate the observed results of hedonic wage studies being pooled in a meta analysis. The counterpart VSL amounts for each of these studies assuming a constant linear rate of tradeoff is indicated by VSL-1 through VSL-5. The indicated WTP function in the diagram indicates the estimated WTP function based on a meta analysis of the five studies. Thus, the WTP value rises with the risk change based on the pooling of results across studies and leads to a flatter WTP function than that implied by linear extrapolation of any particular estimate.

What is potentially confusing about such discussions, which often refer to labor market estimates as "empirical measures of WTP for risk 
reductions," is that for hedonic labor market studies, the estimates are not WTP measures but are WTA measures. In the case of stated preference studies, WTP values are usually the reference point. From a theoretical standpoint, for large risk increases the WTA should be greater than the estimated value based on a linear extrapolation of VSL levels. To the extent that labor market meta analyses are fitting curves such as that in Figure 12.3, the implied VSL should be steadily rising as the risk change increases. That the empirical estimates of VSL do not increase with the level of the fatality risk is a consequence of the self selection of different workers into high risk jobs, as shown in Figure 12.2.

To avoid the complicating considerations of multiple studies across different groups, Figure 12.4 from the EPA SAB report presents the results based on a single study. Once again, WTP should be relabeled WTA since WTA rises with larger positive changes in the risk as indicated, but WTP declines. Interestingly, some EPA officials had suggested that the VSL applied to benefit assessments for a large risk decrease should be greater than for small risk changes. In effect, they

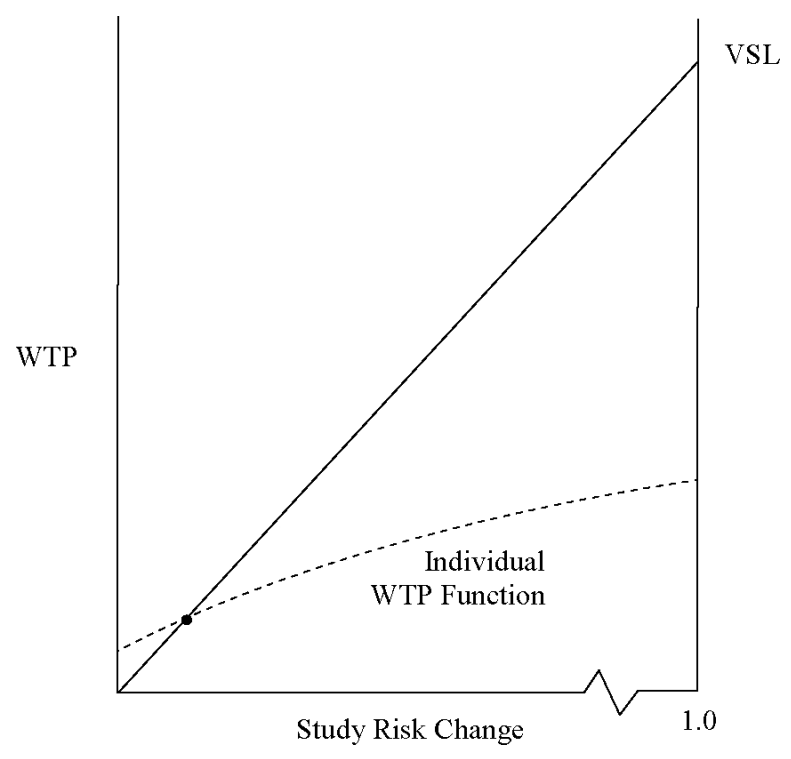

Fig. 12.4 Individual willingness to pay as function of risk level. 
got the relationship backwards, as does Figure 12.4. For large risk decreases the WTP amount is less than the local VSL, and for large risk increases the WTA amount is greater than the local VSL. In terms of the policy application for regulations with large risk effects, it is the WTP amount that is pertinent. Linear extrapolation of the estimated VSL for large risk changes will overstate the WTP amounts for very large changes in risk as people have a positive but diminishing WTP for risk reductions. Whether these effects of major shifts in the risk level are of practical consequence to EPA or other agencies depends on the magnitude of the risks being considered.

Although some environmental risks are relatively large, with the magnitude issue being of concern to the agency, whether they are particularly large compared to the labor market risks that form the basis of most VSL studies is less obvious. For the labor market reference point, consider the risk levels in the recent BLS CFOI data. These annual fatality risks average $1 / 25,000$, which is smaller than the risk levels in other hedonic wage studies. As a result, focusing on these data will provide an upper bound on the extent to which one should view environmental risks as comparatively large.

EPA benefits assessments typically focus on lifetime risks rather than annual risks. Assuming a 40 year work life, an annual occupational fatality risk of $1 / 25,000$ corresponds to a lifetime job-related mortality risk of $1.6 / 1,000$. For a VSL of $\$ 7$ million, the annual required wage compensation is $\$ 280$. The undiscounted lifetime wage premium is $\$ 11,200$. For benefit assessment purposes, such values should be discounted using a reasonable discount rate such as $3 \%$.

To apply my approach to an example of a large environmental risk subject to EPA regulation, I used the Draft Benzene Case Study (EPA, March 2008). ${ }^{3}$ This draft Clean Air Act regulation would reduce the lifetime risks of leukemia to the exposed population. The high risk county affected by the regulation is Brazoria County, for which EPA estimates that the lifetime leukemia risk would decrease from $2 / 10,000$ to $3 \times 10^{-6}$. This risk change is two orders of magnitude, which is a

\footnotetext{
${ }_{3}^{3}$ Data from the draft study are from the Memorandum from Daniel Axelrod to Alan Carlin, National Center for Environmental Economics, U.S. EPA, Nov. 17, 2008.
} 
large percentage risk change. But whether the decrease is two orders of magnitude or even more is not the key issue for determining how much one should modify the local estimate of VSL. The post-regulation leukemia risk is about zero, but what matters is how much the absolute level of the risk has changed.

The absolute magnitude of the lifetime risk reduction of approximately $2 / 10,000$ is not completely outside the range of the annual risk levels that have been considered in hedonic wage studies. How great the risk probability reduction is depends on the nature of the risk exposure. Suppose that the lifetime leukemia risk of $2 / 10,000$ is based on a series of exposures over a ten year period. Then the annual leukemia risk is about $2 / 100,000$. The CFOI annual risk of $1 / 25,000$ is $4 / 100,000$, which is twice as great as this amount. Thus, even using the fatality risk data series posing the smallest risk level, the leukemia risk reduction is of fairly similar magnitude. If the lifetime risk exposure is the result of exposures of even more than ten years, then the annual risk is even smaller.

Whether the environmental risk reduction is large or small depends on how the benefits question is framed. Knowing that there is a lifetime risk reduction of a particular magnitude is not sufficient. Does the risk arise from a one-time exposure that results in leukemia at a particular future date? Or, more reasonably, does the risk arise from a series of exposures over time that produces a future distribution of risk across many future time periods? In all likelihood, focusing on the lifetime risk overstates the risk reduction achieved by the policy in any given year in much the same way as focusing on workers' lifetime risks would overstate their annual fatality risk level.

In the case of labor market risks, the wage compensation for risks occurs in small annual amounts. Policies often do not involve annual payments but instead may involve substantial fixed costs leading to more costs being incurred up front. How the payment mechanism is structured will matter for survey valuations. Most policies are not in fact funded through actual payments of this type, so it is usually the publicly financed benefit valuation thought experiment that is pertinent. 


\section{Latency and Cancer Benefit Issues}

Leukemia and other cancer risks involve a substantial latency period. From the standpoint of benefit assessment, the WTP for reducing these risks at some future date should be discounted by a usual government rate such as $3 \%$. An alternative is to incorporate the latency period aspect into a stated preference survey and ascertain individuals' own rates of time preference with respect to cancer. As fascinating as this might be as an academic exercise, it is unlikely to provide meaningful guidance for policy. Decisions involving an intertemporal component are fraught with error. Among the problems identified in past studies is that of hyperbolic discounting whereby individuals display inordinately high rates of discount for the initial period, as shown in Viscusi et al. (2008). Thus, estimated implicit rates of time preference may largely reflect a form of individual irrationality. Decisions involving risk and uncertainty are also potentially fraught with error so that combining a latency period element with a risk valuation task may lead to an overly complex stated preference task.

Even putting aside both the issues of latency and the magnitude of the risk, more refinement of the benefit estimates for cancer risk reduction is needed. The valuations of cancer risk reduction will differ 
depending on the type of cancer, the associated morbidity effects, and the effect on premature mortality. Some stated preference studies of cancer simply denote the disease as "cancer" with little description of the health consequences. Such studies will not yield meaningful valuations. Unless the respondent knows the characteristics of the health risk being valued and the consequences for personal welfare, the commodity being valued may bear little relationship to what is needed for benefit assessment.

The U.S. EPA (2010) provides a detailed review of the now substantial literature on cancer valuation. The U.S. EPA recommends a $50 \%$ cancer premium, as a "placeholder value," which is in line with the guidance of the Directorate - General Environment of the European Commission. ${ }^{1}$ The U.K. Health and Safety Executive (2001) recommends a value for cancer that is twice as great as the VSL for other causes of death such as road fatalities.

The current U.K. guidance hypothesizes that there is potential heterogeneity in the valuation of a prevented fatality (VPF): "There is evidence that individuals are not indifferent to the cause and circumstances of injury or fatality. For example, in their estimate of benefits from asbestos proposals, HSE currently doubles the VPF figure to allow for individual aversion to dying from cancer, and the additional personal and medical costs." ${ }^{2}$ What is frequently ignored in reference to the U.K. guidelines is the following footnote to this guidance: "There is currently no evidence to support this adjustment. HSE has commissioned a study to investigate public preferences for preventing fatalities due to 'dreaded' risks to inform this issue." ${ }^{3}$ Thus, the U.K. cancer premium currently lacks an empirical foundation.

Two studies that have obtained cancer risk valuations after providing a detailed description of the health consequences are Magat et al. (1996) and Van Houtven et al. (2008). Each of these studies used a risk-risk methodology whereby respondents determined the personal auto accident risk that would be equivalent to a given risk of cancer.

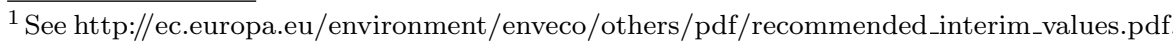
${ }^{2}$ U.K. HM Treasury (2011), p. 62.

${ }^{3}$ For example, the U.K. cancer premium is cited by the U.S. EPA (2010), p. 21, but with no caveat regarding the absence of any empirical evidence for this premium.
} 
The Magat et al. (1996) study presented respondents with detailed descriptions of the health effects of leukemia, where this health effects profile was developed in conjunction with cancer specialists at the Duke Medical Center. One would expect the studies to generate different values because of the different descriptions of the health consequences. However, the extent of the differences between the cancer studies is quite large. Magat et al. (1996) found cancer risks occurring without any latency period as having a value equal to auto accident risks, whereas Van Houtven et al. (2008) found that even with a 5 year latency period, cancer risks were valued three times as highly as auto accident risks. Other studies have yielded different results. Clearly, there is a major research need to refine the estimates of cancer valuations.

The U.S. EPA (2010) has recently proposed attaching a substantial premium to valuation of cancer deaths. Such a premium could be warranted if the morbidity effects of cancer greatly outweigh the morbidity effects of other causes of death, such as the acute risks captured in the CFOI data. Because the mortality benefits from EPA regulations almost invariably focus on cancer prevention, such a premium will enhance the overall economic attractiveness of EPA regulations. 


\section{Dread and Contextual Sources of Variation in Valuing Life: Deaths from Attacks by Terrorists}

How people die matters. Cancer is not the only potential health outcome for which there may be a basis for adopting a different VSL. There may be morbidity effects associated with different kinds of death that will affect the valuation. In addition, the fatalities may be bundled with other types of consequences so that what is valued is not the mortality risk alone but also the risk in the particular context and the attendant losses associated with it. These differences have led to valuations of risks associated with dread, as in Chilton et al. (2006).

A prominent example of distinctive risks of death pertains to victims of terrorism. What is at stake with respect to terrorism risks are not only the lives of the individuals affected but also the general idea that the United States is under foreign attack. Such deaths evoke more general concerns to pertaining to national defense, security, and our overall vulnerability.

Risks of death consequently constitute an economic commodity with a variety of bundled attributes. The nature of the morbidity effects may be consequential, as with cancer, but there are also concerns with respect to how the death occurs (e.g., a missile attack) and the terrorism context in which the death occurs as well. Particularly when questions 
Table 14.1. Subjective level of risk by type of fatality.

\begin{tabular}{lccc}
\hline & $\begin{array}{c}\text { Auto fatality } \\
\text { risk }\end{array}$ & $\begin{array}{c}\text { Natural disaster } \\
\text { fatality risk }\end{array}$ & $\begin{array}{c}\text { Terrorism } \\
\text { fatality risk }\end{array}$ \\
\cline { 2 - 4 } Subjective level of risk & Percent & Percent & Percent \\
\hline Below-average fatality risk & 43.9 & 58.6 & 50.6 \\
Average fatality risk & 47.6 & 34.9 & 41.4 \\
Above-average fatality risk & 8.5 & 6.5 & 8.0 \\
\hline
\end{tabular}

Source: Viscusi and Zeckhauser (2006).

are posed with respect to the public's valuation of risk, issues such as national defense, national pride, and altruism with respect to the prospective victims also come into play.

Because the valuations of reducing terrorism risks may be affected by one's perception of the risk, a useful starting point is to examine risk beliefs regarding deaths from attacks by terrorists. ${ }^{1}$ Table 14.1 provided the results from a national survey administered by Knowledge Networks and analyzed in Viscusi and Zeckhauser (2006). Respondents were given background information on the number of U.S. deaths from auto fatalities, natural disasters, and terrorist attacks. They were then asked to rate their relative risk compared to the average American's. Most people tend to rate their risk levels as being average or below average when compared to the general population. Doing so, in effect, enables them to not find fault with themselves, particularly when elements of personal choice are involved. Consistent with the framing effect of a question format that generates an optimism bias response, few people rate their risk exposure as being above average. Terrorism fatality risk beliefs have a pattern not unlike other causes of death, as a large percentage of the population has below-average risk beliefs. The percentage of respondents in the below-average category is between that for auto fatalities and natural disasters. Interestingly, auto fatality risks have the lowest percentage with below-average risk beliefs, which is inconsistent with the usual claim that people underestimate those risks because of their apparent belief in their control over the risk.

The variables that influence these risk beliefs are examined in Table 14.2, which presents the ordered probit regressions for the terrorism

${ }^{1}$ Robinson (2008) provides a review and recommendations for terrorism risk valuation. 
Table 14.2. Ordered probit regressions of the respondents' subjective terrorism fatality risk perception.

\begin{tabular}{lc}
\hline Independent Variables & $\begin{array}{c}\text { Coefficient } \\
\text { (asymptotic std. error) }\end{array}$ \\
\hline Age & $-0.005^{*}$ \\
& $(0.003)$ \\
Black, non-Hispanic & $0.389^{* *}$ \\
& $(0.139)$ \\
Metropolitan residence & $0.508^{* *}$ \\
More than 6 plane trips per year & $(0.118)$ \\
& $0.545^{\dagger}$ \\
\hline
\end{tabular}

Source: Viscusi and Zeckhauser (2006).

${ }^{\dagger}$ Significant at $10 \%$ level, two-tailed test.

${ }^{*}$ Significant at $5 \%$ level, two-tailed test.

** Significant at $1 \%$ level, two-tailed test.

risk response. Variables that are not statistically significant, including a comprehensive set of locational and demographic variables, are not reported. The specter of the 9/11 attack apparently influences expectations as people who live in metropolitan areas or who fly more than six plane trips per year have higher risk beliefs. Older respondents have lower risk beliefs, while blacks have higher risk beliefs.

Should there be another terrorist attack, how willing are people to support government relief of the victims and their families? For the different terrorism risk belief categories shown in Table 14.1, support for such aid ranges from $72 \%$ to $85 \%$ of the population. As indicated in Table 14.3, among the more interesting factors linked to support of assistance to terrorism attack victims are that current smokers, women, blacks, and those with average terrorism risk beliefs are supportive of such aid, while older respondents and Republicans are less supportive.

Although the 9/11 attack was a surprise to most Americans, a substantial share of the population claims that they knew about the risk all along. This perceptional bias is a close relative of a form of hindsight bias that Viscusi and Zeckhauser (2005) term recollection bias. Three samples of respondents in 2002, 2003, and 2004 were asked the following question: "Take yourself back to the World Trade Center disaster. Do you believe that the risk of a terrorist attack over the next year on an airplane is higher or lower than you thought it was before 
Table 14.3. Ordered probit regressions for government relief for terrorism victims.

\begin{tabular}{lc}
\hline Independent variables & $\begin{array}{c}\text { Relief for } \\
\text { terrorism victims }\end{array}$ \\
\hline Age & $-0.011^{* *}$ \\
& $(0.003)$ \\
Female & $0.198^{\dagger}$ \\
& $(0.106)$ \\
Black, non-Hispanic & $0.570^{*}$ \\
Years of education & $(0.229)$ \\
& $-0.041^{\dagger}$ \\
Republican & $(0.025)$ \\
& $-0.298^{* *}$ \\
Current smoker & $(0.110)$ \\
& $0.326^{*}$ \\
More than 6 plane trips per year & $(0.136)$ \\
Above-average terrorism fatality risk & 0.356 \\
& $(0.327)$ \\
Below-average terrorism fatality risk & $-0.643^{* *}$ \\
& $(0.211)$ \\
& $-0.408^{* *}$ \\
\hline
\end{tabular}

Source: Viscusi and Zeckhauser (2006).

${ }^{\dagger}$ Significant at $10 \%$ level, two-tailed test.

* Significant at $5 \%$ level, two-tailed test.

${ }^{* *}$ Significant at $1 \%$ level, two-tailed test.

Table 14.4. Percentage change in terrorist risk estimates after September 11.

\begin{tabular}{lccc}
\hline & $\begin{array}{c}\text { 2002 Sample } \\
(N=94)\end{array}$ & $\begin{array}{c}\text { 2003 Sample } \\
(N=117)\end{array}$ & $\begin{array}{c}2004 \text { Sample } \\
(N=122)\end{array}$ \\
\hline Risk is now higher & 43 & 54 & 33 \\
Risk is same as before September 11 & 17 & 24 & 34 \\
Risk is now lower & 40 & 22 & 33 \\
\hline
\end{tabular}

Source: Viscusi and Zeckhauser (2005).

the September 11th disaster?" Table 14.4 presents a summary of the responses to this question. A surprisingly low percentage views the risk as being higher than they thought it was before the attack despite the likelihood that expectation of a terrorist attack was probably not perceived as a significant risk before the 9/11 attack. This apparent bias in risk perceptions has ramifications for the public's support of anti-terrorism measures as shown by results in a survey for tradeoffs involving potential compromise of civil liberties. Respondents subject 
to September 11 recollection bias are less likely to favor targeting passengers for screening, presumably because they do not believe that there is an enhanced threat that must be addressed.

Anti-terrorism policies also may entail tradeoffs borne by the individual. Instead of targeting people for screening, there may be a choice of waiting longer in line for screening. In this instance the tradeoff is between civil liberties and waiting time. For scenarios in which the screening was designed to only affect others, not the respondent, the willingness to favor risk profiling based on personal characteristics ("the person's age, race, gender, national origin, appearance, and baggage") increased from $45 \%$ to $74 \%$ as the waiting time increased from 10 minutes to 60 minutes. As the regression results in Table 14.5 indicate, each 10 minute period of waiting time increases the overall percentage supporting targeting by $4 \%$. Nonwhites, who may have been previous victims of discrimination and who may believe that they will be targeted, are $27 \%$ less likely to support a targeting policy.

To analyze different societal preferences toward reducing risks, Viscusi $(2009 \mathrm{~b})$ analyzed results of a stated preference experiment using a nationally representative sample. The survey focused on two sets of risk-risk tradeoffs. How much would one value the risks of death from terrorism as compared to comparable risks from natural disasters? How are terrorism risks valued compared to traffic-related deaths? And

Table 14.5. Determinants of the probability of favoring targeting of passengers for airport screening.

\begin{tabular}{lcc}
\hline Independent variable & \multicolumn{2}{c}{ Coefficient (std. error) } \\
\hline Waiting time (in min.) & $0.0038^{* *}$ & $0.0065^{* * *}$ \\
& $(0.0015)$ & $(0.0022)$ \\
Respondents targeted for screening & 0.0190 & 0.1870 \\
& $(0.0627)$ & $(0.1140)$ \\
Non-white & $-0.2653^{* * *}$ & $-0.2655^{* * *}$ \\
Waiting time $\times$ Respondent targeted for screening & $(0.0696)$ & $(0.0697)$ \\
& & $-0.0052^{*}$ \\
& & $(0.0030)$ \\
\hline
\end{tabular}

Source: Viscusi and Zeckhauser (2003).

*Indicates coefficient is significantly different from zero at $10 \%$ level, two-sided test.

** Indicates coefficient is significantly different from zero at $5 \%$ level, two-sided test.

*** Indicates coefficient is significantly different from zero at $1 \%$ level, two-sided test. 
Sample Terrorism Question:

Suppose you can vote for one of two different policies that cost the same amount but reduce different kinds of risks. Traffic safety policies reduce isolated deaths. The terrorism policy prevents deaths from a single major attack. Which of the two policies would you prefer?

Type of Deaths Prevented

\begin{tabular}{c} 
Traffic Safety \\
\hline Isolated Accidents \\
150 \\
Policy 1
\end{tabular}

Terrorism Policy

Average Number of Deaths Prevented

Policy 1
Major Terrorism Attack 50
Policy 2

Fig. 14.1 Example of risk tradeoff question.

Table 14.6. Relative risk valuations after accounting for risk beliefs.

\begin{tabular}{|c|c|}
\hline Fatality risk tradeoff categories & Implied relative valuations \\
\hline $\begin{array}{c}\text { Average disaster death risk/ } \\
\text { average traffic death risk }\end{array}$ & 1.7888 \\
\hline $\begin{array}{l}\text { Above-average terrorism death risk/ } \\
\text { average traffic death risk }\end{array}$ & 0.6794 \\
\hline $\begin{array}{l}\text { Average terrorism death risk/ } \\
\text { average traffic death risk }\end{array}$ & 0.9940 \\
\hline $\begin{array}{l}\text { Below-average terrorism death risk/ } \\
\text { average traffic death risk }\end{array}$ & 1.3642 \\
\hline $\begin{array}{l}\text { Above-average terrorism death risk/ } \\
\text { average disaster death risk }\end{array}$ & 0.3798 \\
\hline $\begin{array}{l}\text { Average terrorism death risk/ } \\
\text { average disaster death risk }\end{array}$ & 0.5557 \\
\hline $\begin{array}{l}\text { Below-average terrorism death risk/ } \\
\text { average disaster death risk }\end{array}$ & 0.7626 \\
\hline
\end{tabular}

how are traffic-related deaths valued compared to natural disasters? Figure 14.1 presents an example of such a survey question in which terrorism deaths are compared to traffic-related risks.

The results of the series of paired comparisons based on questions such as that in Figure 14.1 are reported in Table 14.6. A principal result of the study is that although the number of deaths is the same in each case, preventing 0.56 terrorism deaths is equivalent to preventing a death from natural disasters for those with average risk beliefs. Thus, respondents value terrorism risks by a factor that is more than double the value attached to victims of natural disasters. Terrorism deaths are valued almost the same as traffic-related deaths for those with average risk beliefs. The different valuation amounts in Table 14.6 are quite responsive to individuals' risk beliefs, as the relative valuations are 
boosted by believing that one faces above average risks and reduced if the risks are believed to be below average.

The high valuations of terrorism deaths compared to natural disasters do not stem from a difference in risk perceptions whereby people thought they might be victims of a terrorist attack but not a natural disaster. The analysis controlled for differences in risk beliefs, personal characteristics, and other factors likely to influence valuations. Political factors also came into play, as those who are registered Republicans placed a higher valuation on the terrorism risks even accounting for differences in income levels and other likely determinants of the valuation amounts.

While studies such as this provide evidence on a risk-money tradeoff, their perspective is different than a traditional VSL study. A hedonic labor market analysis of job market safety only captures the individual's valuation of personal risks. In contrast, these stated preference valuations yield society's general valuation of the hazard, where this value will include the personal risk but also may include a potentially substantial altruistic component irrespective of whether one is at risk personally.

The high valuation of terrorism risks as compared to traffic-related risks is striking in that people are much more likely to view themselves at a higher risk of personal death from motor-vehicle accidents, thus leading to a strong personal risk valuation component as part of their valuation response. The low valuation of natural disaster risks also may stem from a belief that those exposed to the risk exhibit a form of moral hazard. The analysis of attitudes towards victims of natural disasters in Viscusi and Zeckhauser (2003) found that individuals who continued to expose themselves to natural disasters after previously experiencing catastrophic losses were not regarded as being highly deserving of continued public assistance. However, the high valuation of preventing terrorist attacks from hand held missiles, as found by Smith et al. (2009) suggests that there is a premium for terrorism deaths.

This kind of result pertaining to personal responsibility for risk exposures very much parallels a finding in the United Kingdom by Covey et al. (2010). Their U.K. study focused on the public's valuation of reducing risks of people who exhibit irresponsible behavior. The risk 
context they considered was that of railway trespassers and suicides involving railroads. Their finding was that the public placed a lower value on reducing the risks of life to those who were willing to expose themselves to risk by, for example, intentionally being killed by an oncoming train.

Both the U.S. natural disasters results and the U.K. railroad results could reflect two sets of influences. First, people who have self-selected into choosing risky pursuits by either continuing to expose themselves to risks of natural disasters or taking high risk actions with respect to railroad hazards have revealed through their actions that they place a lower value on risks to their life. As a consequence, a lower societal value for reducing their risks is simply a valuation that is consistent with the person's own revealed preferences and evidence of moral hazard. Second, it is also possible that respondents view such risks as hazards that will affect others and not necessarily themselves to the extent that people believe that they are responsible risk takers even if others are not. However, even accounting for differences in individual experiences of natural disasters in Viscusi (2009b), there remains a substantial gap in valuations of the risks of terrorism versus natural disasters. 


\section{Should the VSL Be Added to the Present Value of Economic Damages?}

There have been efforts in legal contexts to use the VSL measure to determine levels of compensation for wrongful death cases. This approach, known as hedonic damages, has been rejected by most courts but has been admitted in some state jurisdictions. To the extent that compensatory damages serve an insurance function, setting compensation amounts at the level of VSL provides excessive insurance. In situations in which the injury arises in a market context, such as product-related injuries addressed by product liability, compensation based on the VSL levels will force people to buy excessive amounts of insurance since the liability costs will be incorporated in the product price. Use of VSL amounts in legal contexts is, however, appropriate for determining the cost-risk tradeoff under a negligence standard or for setting the level of punitive damages when deterrence is a matter of concern, as shown in Hersch and Viscusi (2010b).

Notwithstanding economists' reservations about using VSL as the standard approach for setting compensatory damages amounts, Posner and Sunstein (2005) advocate an even more generous compensatory damages formulation than using VSL for wrongful death cases. Here 
I will briefly review their proposal and its limitations. ${ }^{1}$ Although the focus of their discussion is the use of VSL in the courtroom, since the optimal deterrence amount is never less than the optimal insurance amount for wrongful death, their proposal has potential implications for valuing government regulations as well.

The Posner-Sunstein proposal is to provide two different components of compensatory damages. The first component is the standard compensation for economic loss consisting of the present value of lost earnings and medical costs. They propose as the second component augmenting this compensation with the VSL amount. They describe four different methods for calculating the VSL value. The four different ways that they suggest for calculating the VSL are of potential interest from the standpoint of analyzing the heterogeneity of VSL for government policy. Irrespective of the method used to calculate the VSL, their procedure ensures that the payment amount will provide both excessive deterrence and excessive insurance. There is no sound economic rationale for damages at the levels they propose, and they do not offer such a rationale. In what appears to be enormous understatement, they observe that their proposal would "have a significant impact on tort awards, especially for the elderly in non-hedonic loss states."

The first approach that the courts might use is to use to calculate the government number for VSL. This is ultimately the approach that they suggest that judges should adopt. Unlike the present value of lost earnings and medical cost number, this VSL will not be specific to the individual and that person's age, income, gender, health status, and other factors. It is a one size fits all approach not unlike what government agencies generally do when valuing regulatory policies. However, government policies are generally protective of broad population groups, not single individuals. As a result, adopting a uniform VSL for compensatory damages for all wrongful death cases is inconsistent with common law practices for setting compensation for personal injury cases in which the compensation is linked to what the particular injured party has lost. At a more fundamental level, there is

${ }^{1}$ For a more extensive critique, see Viscusi (2007). 
also the question of what is the "government number" in that the VSL number differs not only across agencies but also within agencies. For example, air pollution and water pollution regulations by EPA are valued at different VSL amounts. Note too that the government has never adopted the VSL for purposes of compensation but only for benefit assessment.

The second approach Posner and Sunstein suggest for ascertaining the VSL is to determine the victim's VSL. Thus if $R$ is the compensation the person received for risk $q$, the VSL amount that would be used is $R / q$. Because the victim is deceased, a stated preference survey asking the person the value of $R$ for risk $q$ is not feasible. The difficulty with the person-specific attempt to ascertain the risk compensation $R$ is that rarely do we have individual-specific information on the level of $R$ or the value of $q$. Using the CFOI data it is often possible to estimate the value of $q$ for the worker's industry-occupation cell or some other basis, but not at the refined level of the individual's job. Wage equation estimates could also be used at an aggregative level so as to determine the wage-risk tradeoff associated with the person's job, assuming of course that the individual who died was employed.

Their third approach to assessing the VSL for the deceased is to ask how much the victim would have paid to avoid the risk and then infer a VSL from that calculation. This procedure is a hypothetical calculation undertaken in hindsight on behalf of the person who is deceased. One could use evidence from the person's other risk-taking activities, whether risks on the job or risky personal consumption activities such as smoking, to make some inferences about the individual's personal VSL. However, from the standpoint of ascertaining VSL estimates that reflect refined degrees of heterogeneity, this procedure appears to be much less reliable than obtaining ex ante valuations using stated preference surveys. The temporal reference point for government policies is also ex ante, which makes such an analysis feasible. However, the court system compensates people after injuries and deaths so it does not have leeway in this regard.

The fourth approach suggested by Posner and Sunstein for evaluating the VSL is to ask the jury to set a "value of life's pleasures lost by the victim." This concept is entirely different from the VSL approach, 
although they suggest that it is simply an alternative procedure for calculating VSL. The VSL reflects attitudes toward lotteries involving small probabilities of death. The value of life's pleasures is a quite different concept than that embodied in the VSL. The economic content of the value of life's pleasures concept is also not clear. Is this damages amount the amount of money that the person must be paid after death to be indifferent to life or death? Since the person does not have a utility function after death, there is no operational significance to this approach. Perhaps the task could be framed as the bequest amount that would have restored the deceased's welfare using the bequest function of the deceased. Or perhaps another conceptualization for the value of life's pleasures is the WTP amount to avoid certain death. In either case, the amount that is being calculated is quite different conceptually from the VSL, and it is also unclear whether any of these formulations is consistent with standard jury instructions.

Although the Posner-Sunstein proposal is not a workable approach to setting damages for tort cases or for determining benefit values for regulatory analyses, their discussion highlights the importance of recognizing the role of heterogeneity. Damages in wrongful death and personal injury cases generally are linked to the amounts that are lost by the specific victims. Their approach abandons the traditional focus of court awards on the losses in the particular case. The heterogeneity of these losses across victims is a central component of damages calculations but is ignored by their proposal. In much the same way, government regulations should be assessed using the specific benefit values of those who are being protected by the regulation. Fortunately, those protected often include a broad cross section of society not unlike the U.S. working population so that applying labor market estimates of VSL is often a reasonable form of benefits transfer. 


\section{Conclusion}

The VSL has been an integral part of the government's benefits assessment for almost 30 years. Much of the continued controversy created by noneconomists over the approach has been based on the misunderstanding of the "economic" value of life. There is often a tendency to equate this measure with accounting value such as the value of a person's taxes or income. The controversy and confusion has been so great that Cameron (2008) has suggested abandoning the VSL terminology. Because of this confusion, the opposition to the VSL approach is often misguided. Fortunately, the VSL is likely to remain a standard component of government analysts' toolkit.

Throughout its history the use of the VSL approach has been quite supportive of meaningful risk regulation policies. Thus, not only is it the correct economic approach, but it also places a much more substantial value on the lives that will be saved than did previous measures such as the present value of lost earnings. Although some critics have proposed that no dollar values be used at all, given the emphasis on showing that the benefits of regulation exceed the value of the costs, the practical consequence of this approach will not be to elevate their value but to 
diminish their importance in regulatory policymaking. Rather, treating some risk reductions as "priceless" may make them "worthless."

With improved fatality rate data and survey data, researchers have greatly expanded the questions that can be addressed. No longer is research limited to estimating an average VSL for the sample. The estimates of heterogeneity of VSL and analyses of the sources of heterogeneity are becoming more refined both for the labor market and for survey populations. A challenge raised by this increased refinement in estimates of VSL heterogeneity is that there are new policy challenges that are being presented. Should the policy effects be valued based on the willingness to pay of those affected, as is the basic economic norm? If that approach is to be followed, will it recognize the legitimate heterogeneity in these valuations? The task for policymakers is to decide which estimates of VSL heterogeneity are meaningful reflections of differences in individual preferences and which are not. Even if the VSL estimates for different groups are valid, there is the subsequent issue of whether they should be incorporated in the benefit assessment process. For many broadly based government programs, average valuations will suffice. But for policies affecting specific sub-populations, such as airline passengers, recognition of the heterogeneity of VSL is essential to developing efficient risk policies. 


\section{References}

Ackerman, F. and L. Heinzerling (2004), Priceless: On Knowing the Price of Everything and the Value of Nothing. New York: The New Press.

Aldy, J. E. and W. K. Viscusi (2007), 'Age differences in the value of statistical life: Revealed preference evidence'. Review of Environmental Economics and Policy 1(2), 241-260.

Aldy, J. E. and W. K. Viscusi (2008), 'Adjusting the value of a statistical life for age and cohort effects'. Review of Economics and Statistics 90(3), 573-581.

Black, D. A. and T. J. Kniesner (2003), 'On the measurement of job risk in hedonic wage models'. Journal of Risk and Uncertainty 27(3), 205-220.

Blomquist, G. C., M. Dickie, and R. M. O'Conor (2011), 'Willingness to pay for improving fatality risks and asthma symptoms'. Resource and Energy Economics 33(2), 410-425.

Bowland, B. J. and J. C. Beghin (2001), 'Robust estimates of value of a statistical life for developing economies'. Journal of Policy Modeling 23(4), 385-396.

Cameron, T. (2008), 'The value of a statistical life: [They] do not think it means what [we] think it means'. AERE Newsletter 28. 
Chilton, S., M. Jones-Lee, F. Kiraly, H. Metcalf, and W. Pang (2006), 'Dread risks'. Journal of Risk and Uncertainty 33(3), 165-182.

Cobacho Tornel, M. B., Á.. López Nicolas, and J. M. Ramos Parreño (2010), 'Mortality cost of smoking in Spain'. Revista Española de Salud Pública 84(3), 271-280.

Covey, J., A. Robinson, M. Jones-Lee, and G. Loomes (2010), 'Responsibility, scale, and the valuation of rail safety'. Journal of Risk and Uncertainty 40(1), 85-108.

Cropper et al., M. (2007), 'SAB Advisory on EPA's issues in valuing mortality-risk reduction'. Memorandum from the Chair, Science Advisory Board, and the Chair, Environmental Economics Advisory Committee, to EPA Administrator Stephen L. Johnson. EPA-SAB08-01.

Eeckhoudt, L. R. and J. K. Hammitt (2001), 'Background risk and the value of a statistical life'. Journal of Risk and Uncertainty 23(3), 261-279.

European Commission (2001), 'Recommended interim values for the value of preventing a fatality in DG Environment cost benefit analysis'. http://ec.europa.eu/environment/enveco/others/pdf/ recommended_interim_values.pdf.

Evans, M. F. and G. Schaur (2009), 'A quantile estimation approach to identify income and age variation in the value of a statistical life'. SSRN Working Paper.

Evans, M. F. and V. K. Smith (2010), 'Measuring how risk tradeoffs adjust with income'. Journal of Risk and Uncertainty 40(1), 33-55.

Graham, J. D. (2008), 'Saving lives through administrative law and economics'. University of Pennsylvania Law Review 157, 395-540.

Hakes, J. K. and W. K. Viscusi (2007), 'Automobile seatbelt usage and the value of statistical life'. Southern Economic Journal 73(3), 659-676.

Hammitt, J. K. (2007), 'Valuing changes in mortality risk: Lives saved versus life years saved'. Review of Environmental Economics and Policy 1(2), 228-240.

Hammitt, J. K. and K. Haninger (2010), 'Valuing fatal risks to children and adults: Effects of disease, latency, and risk aversion'. Journal of Risk and Uncertainty 40(1), 57-83. 
Hara Associates, Inc. (2000), Benefit/cost Analysis of Proposed Tobacco Products Information Regulations. Ottawa, Ontario. Prepared for Health Canada and Consulting and Audit Canada, June 5, 2000.

Hersch, J. (1998), 'Compensating differentials for gender-specific job injury risks'. American Economic Review 88(3), 598-607.

Hersch, J. and W. K. Viscusi (2010a), 'Immigrant status and the value of statistical life'. Journal of Human Resources 45(3), 749-771.

Hersch, J. and W. K. Viscusi (2010b), 'Saving lives through punitive damages'. Southern California Law Review 83(2), 229-262.

Jones-Lee, M. W., M. Hammerton, and P. R. Philips (1985), 'The value of safety: Results of a national sample survey'. Economic Journal 95, 49-72.

Kaplow, L. (2005), 'The value of statistical life and the coefficient of relative risk aversion'. Journal of Risk and Uncertainty 31(1), $23-34$.

Kniesner, T. J. and J. D. Leeth (2009), 'Hedonic wage equilibrium: Theory, evidence and policy'. Foundations and Trends in Microeconomics 5(4), 229-299.

Kniesner, T. J. and W. K. Viscusi (2005), 'Value of a statistical life: Relative position vs. relative age'. American Economic Review 95(2), 142-146.

Kniesner, T. J., W. K. Viscusi, C. Woock, and J. P. Ziliak (2011), 'The value of statistical life: Evidence from panel data'. SSRN Working Paper 1739139. Forthcoming, Review of Economics and Statistics.

Kniesner, T. J., W. K. Viscusi, and J. P. Ziliak (2006), 'Life-cycle consumption and the age-adjusted value of life'. Contributions to Economic Analysis \& Policy 5(1), 1-34.

Kniesner, T. J., W. K. Viscusi, and J. P. Ziliak (2010), 'Policy relevant heterogeneity in the value of statistical life: New evidence from panel data quantile regressions'. Journal of Risk and Uncertainty 40(1), $15-31$.

Kochi, I., B. Hubbell, and R. Kramer (2006), 'An empirical Bayes approach to combining and comparing estimates of the value of a statistical life for environmental policy analysis'. Environmental and Resource Economics 34(3), 385-406. 
Krupnick, A. (2007), 'Mortality-risk valuation and age: Stated preference evidence'. Review of Environmental Economics and Policy 1(2), 261-282.

Leeth, J. D. and J. Ruser (2003), 'Compensating wage differentials for fatal and nonfatal injury risk by gender and race'. Journal of Risk and Uncertainty 27(3), 257-277.

Liu, J.-T., J. K. Hammitt, and J.-L. Liu (1997), 'Estimated hedonic wage function and value of life in a developing country'. Economics Letters 57(3), 353-358.

Lutter, R., J. F. Morrall, III, and W. K. Viscusi (1999), 'The cost-perlife saved cutoff for safety-enhancing regulations'. Economic Inquiry 37(4), 599-608.

Magat, W. A., W. K. Viscusi, and J. Huber (1996), 'A reference lottery metric for valuing health'. Management Science 42(8), 1118-1129.

Miller, T. R. (2000), 'Variations between countries in values of statistical life'. Journal of Transport Economics and Policy 34(2), 169-188.

Moore, M. J. and W. K. Viscusi (1988a), 'Doubling the estimated value of life: Results using new occupational fatality data'. Journal of Policy Analysis and Management 7(3), 476-490.

Moore, M. J. and W. K. Viscusi (1988b), 'The quantity-adjusted value of life'. Economic Inquiry 26(3), 369-388.

Moore, M. J. and W. K. Viscusi (1990a), 'Discounting environmental health risks: New evidence and policy implications'. Journal of Environmental Economics and Management 18(2), S51-S62.

Moore, M. J. and W. K. Viscusi (1990b), 'Models for estimating discount rates for long-term health risks using labor market data'. Journal of Risk and Uncertainty 3(4), 381-401.

Mrozek, J. R. and L. O. Taylor (2002), 'What determines the value of life? A meta-analysis'. Journal of Policy Analysis and Management 21(2), 253-270.

Posner, E. A. and C. R. Sunstein (2005), 'Dollars and death'. University of Chicago Law Review 72(2), 537-598.

Robinson, L. A. (2007), 'How U.S. government agencies value mortality risk reductions'. Review of Environmental Economics and Policy 1(2), 283-299. 
Robinson, L. A. (2008), 'Valuing mortality risk reductions in homeland security analysis. Final Report to U.S. Customs and Border Protection'. Department of Homeland Security, under contract to Industrial Economics.

Scharff, R. L. and W. K. Viscusi (2009), 'Heterogeneous rates of time preference and the decision to smoke'. Economic Inquiry, doi:10.1111/j.1465-7295.2009.00191.x.

Shepard, D. S. and R. J. Zeckhauser (1984), 'Survival versus consumption'. Management Science 30(4), 423-439.

Smith, V. K., M. F. Evans, and D. H. Taylor, Jr. (2004), 'Do the nearelderly value mortality risks differently?'. Review of Economics and Statistics 86(1), 423-429.

Smith, V. K., C. Mansfield, and L. Clayton (2009), 'Valuing a homeland security policy: Countermeasures for the threats from should mounted missiles'. Journal of Risk and Uncertainty 38(3), 215-243.

Thaler, R. H. and S. Rosen (1975), 'The value of saving a life: Evidence from the labor market'. In: N. E. Terleckyj (ed.): Household Production and Consumption. New York: Columbia University Press.

U.K. Health and Safety Executive (2001), Reducing Risks, Protecting People: HSE's Decision-Making Process. http://www.hse.gov.uk/ risk/theory/r2p2.pdf.

U.K. HM Treasury (2011), The Green Book: Appraisal and Evaluation in Central Government: Treasury Guidance. London: TSO. http://www.hm-treasury.gov.uk/d/green_book_ complete.pdf.

U.S. Department of Transportation (2008), 'Office of the assistant secretary for transportation policy memorandum: Treatment of the economic value of statistical life in departmental analyses'. http://ostpxweb.dot.gov/policy/reports/080205.htm.

U.S. Environmental Protection Agency (2002), 'Technical addendum: Methodologies for the benefit analysis of the Clear Skies Initiative'. http://www.epa.gov/clearskies/tech_ adden.pdf.

U.S. Environmental Protection Agency (2010), 'Valuing mortality risk reductions for environmental policy: A white paper'. SAB Review Draft. 
Van Houtven, G., M. B. Sullivan, and C. Dockins (2008), 'Cancer premiums and latency effects: A risk tradeoff approach for valuing reduction'. Journal of Risk and Uncertainty 36(2), 179-200.

Viscusi, W. K. (1978a), 'Labor market valuations of life and limb: Empirical evidence and policy implications'. Public Policy 26(3), 359-386.

Viscusi, W. K. (1978b), 'Wealth effects and earnings premiums for job hazards'. Review of Economics and Statistics 60(3), 408-416.

Viscusi, W. K. (1979), Employment Hazards: An Investigation of Market Performance. Cambridge: Harvard University Press.

Viscusi, W. K. (1992), Fatal Tradeoffs: Public and Private Responsibilities for Risk. New York: Oxford University Press.

Viscusi, W. K. (1993), 'The value of risks to life and health'. Journal of Economic Literature 31, 1912-1946.

Viscusi, W. K. (2002), Smoke-Filled Rooms: A Postmortem on the Tobacco Deal. Chicago: University of Chicago Press.

Viscusi, W. K. (2003), 'Racial differences in labor market values of a statistical life'. Journal of Risk and Uncertainty 27(3), 239-256.

Viscusi, W. K. (2004), 'The value of life: Estimates with risks by occupation and industry'. Economic Inquiry 42(1), 29-48.

Viscusi, W. K. (2007), 'The flawed hedonic damages measure of compensation for wrongful death and personal injury'. Journal of Forensic Economics 20(2), 113-135.

Viscusi, W. K. (2009a), 'The devaluation of life'. Regulation and Governance 3(2), 103-127.

Viscusi, W. K. (2009b), 'Valuing risks of death from terrorism and natural disasters'. Journal of Risk and Uncertainty 38(3), 191-213.

Viscusi, W. K. (2010), 'The heterogeneity of the value of statistical life: Introduction and overview'. Journal of Risk and Uncertainty 40(1), $1-13$.

Viscusi, W. K. and J. E. Aldy (2003), 'The value of a statistical life: A critical review of market estimates throughout the world'. Journal of Risk and Uncertainty 27(1), 239-256.

Viscusi, W. K. and J. E. Aldy (2007), 'Labor market estimates of the senior discount for the value of statistical life'. Journal of Environmental Economics and Management 53(3), 377-392. 
Viscusi, W. K. and J. Hersch (2001), 'Cigarette smokers as job risk takers'. Review of Economics and Statistics 83(2), 269-280.

Viscusi, W. K. and J. Hersch (2008), 'The mortality cost to smokers'. Journal of Health Economics 27(4), 943-958.

Viscusi, W. K., J. Huber, and J. Bell (2008), 'Estimating discount rates for environmental quality from utility-based choice experiments'. Journal of Risk and Uncertainty 37(2/3), 199-220.

Viscusi, W. K. and M. J. Moore (1989), 'Rates of time preference and valuations of the duration of life'. Journal of Public Economics 38(3), 297-317.

Viscusi, W. K. and R. J. Zeckhauser (2003), 'Sacrificing civil liberties to reduce terrorism risks'. Journal of Risk and Uncertainty 26(2/3), 99-120.

Viscusi, W. K. and R. J. Zeckhauser (2005), 'Recollection bias and the combat of terrorism'. Journal of Legal Studies 34(1), 27-55.

Viscusi, W. K. and R. J. Zeckhauser (2006), 'National survey evidence on disasters and relief: Risk beliefs, self-interest, and compassion'. Journal of Risk and Uncertainty 33(1/2), 13-36. 
Copyright of Foundations \& Trends in Microeconomics is the property of Now Publishers and its content may not be copied or emailed to multiple sites or posted to a listserv without the copyright holder's express written permission. However, users may print, download, or email articles for individual use. 